\title{
A NUMERICAL ANALYSIS OF SELECTED ELASTIC-PLASTIC FRACTURE PARAMETERS FOR DEN(T) PLATES UNDER PLANE STRAIN CONDITIONS
}

\author{
M. GRABA \\ Kielce University of Technology \\ Faculty of Mechatronics and Mechanical Engineering \\ Department of Manufacturing Engineering and Metrology \\ Al. 1000-lecia PP 7, 25-314 Kielce, POLAND \\ E-mail:mgraba@tu.kielce.pl
}

\begin{abstract}
This paper provides a numerical analysis of selected parameters of fracture mechanics for double-edge notched specimens in tension, $\mathrm{DEN}(\mathrm{T})$, under plane strain conditions. The analysis was performed using the elastic-plastic material model. The study involved determining the stress distribution near the crack tip for both small and large deformations. The limit load solution was verified. The $J$-integral, the crack tip opening displacement, and the load line displacement were determined using the numerical method to propose the new hybrid solutions for calculating these parameters. The investigations also aimed to identify the influence of the plate geometry and the material characteristics on the parameters under consideration. This paper is a continuation of the author's previous studies and simulations in the field of elastic-plastic fracture mechanics [4$6,16,17,31]$.
\end{abstract}

Key words: $\operatorname{DEN}(\mathrm{T})$, fracture mechanics, $Q$-stress, maximum stress, $J$-integral, CTOD, load line displacement, limit loads.

\section{Introduction (based on [4-6])}

The stress distribution near the crack tip for elastic-plastic materials - the HRR solution and the O'Dowd and Shih theory [4-6]

The basic solution used for determining the stress distribution in elastic-plastic materials was first published in 1968 [1, 2]. It is now known as the Hutchinson-Rice-Rosengren (HRR) solution

$$
\sigma_{i j}=\sigma_{0}\left(\frac{J}{\alpha \sigma_{0} \varepsilon_{0} I_{n} r}\right)^{\frac{1}{1+n}} \tilde{\sigma}_{i j}(\theta, n)
$$

where $r$ and $\theta$ are the polar coordinates of the coordinate system located at the crack tip, $\sigma_{i j}$ are the stress tensor components, $J$ is the $J$-integral, $n$ is the RO exponent, $\alpha$ is the RO constant, $\sigma_{0}$ is the yield stress, and $\varepsilon_{0}$ is the strain related to $\sigma_{0}$ through $\varepsilon_{0}=\sigma_{0} / E$. The functions $\tilde{\sigma}_{i j}(n, \theta)$ and $I_{n}(n)$ are found by solving a fourth-order non-linear homogenous differential equation separately for the plane stress and plane strain conditions [4-6].

The HRR solution, which is valid for the states of plane stress and plane strain, contains only the first term of the infinite series [4-6]. Many numerical analyses have shown that the results obtained for the plane strain conditions by means of the HRR solution are different from those calculated using the finite element method (FEM) [4-6] (see Fig.2). The difference can be eliminated by adding more terms to the HRR solution [4-6]. 


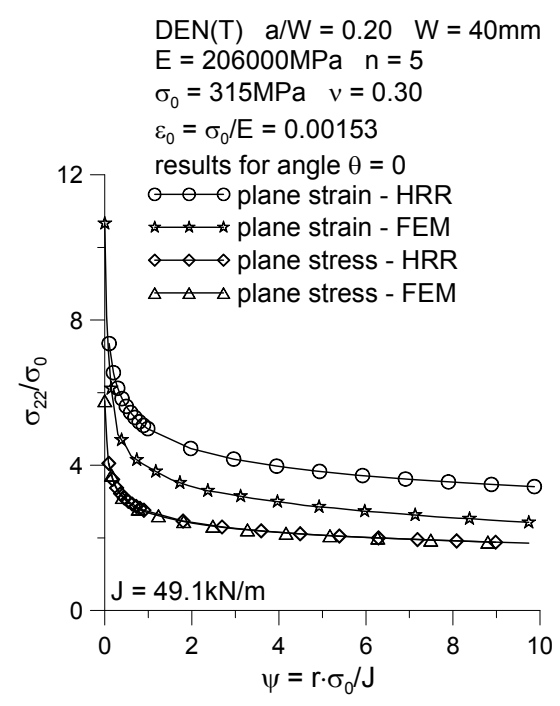

Fig.1. The comparison of the FEM results with those obtained through the HRR solution for DEN(T) specimens under plane stress and plane strain (based on [4-6]).

There have been many attempts to deal with the difference between the analytical and real descriptions of the stress field. The numerical solution is considered to provide the actual stress distribution. The approach proposed by O'Dowd and Shih $[7,8]$ is quite simple in nature. They assume that the FEM results are exact and that the difference between the numerical and the HRR results can be calculated. They propose that the stress field near the crack tip should be described using the following formula [4-6]

$$
\sigma_{i j}=\left(\sigma_{i j}\right)_{H R R}+Q \sigma_{0} \hat{\sigma}_{i j}(\theta)
$$

where $\left(\sigma_{i j}\right)_{H R R}$ is the HRR solution [4-6], $\hat{\sigma}_{i j}(\theta ; n)$ are the functions determined numerically and $Q$ is the parameter that takes into account the difference between the HRR and numerical solutions [4-6]

$$
Q=\frac{\left(\sigma_{\theta \theta}\right)_{F E M}-\left(\sigma_{\theta \theta}\right)_{H R R}}{\sigma_{0}} \quad \text { for } \quad \theta=0 \quad \text { and } \quad \frac{r \sigma_{0}}{J}=2
$$

where $\left(\sigma_{\theta \theta}\right)_{F E M}$ is the value of stress calculated using the FEM and $\left(\sigma_{\theta \theta}\right)_{H R R}$ is the value of stress determined from the HRR solution [4-6]. Both terms should be calculated for the distance $r=2 J / \sigma_{0}$ in the direction characterized by $\theta=0$ [4-6]; when $\theta=0$, the function $\hat{\sigma}_{\theta \theta}(\theta=0)$ (in Eq.(1.2)) is equal to 1 [4-6].

Various numerical calculations have confirmed that for the plane stress state the $Q$-parameter is equal to zero, whereas for the plane strain state the $Q$-parameter is generally less than zero (see Fig.2) [4-6].

The O'Dowd and Shih theory to describe the stress field in front of the crack tip seems to be the right solution when plane strain is predominant and when we know the value of the $Q$-stress. Catalogs of numerical solutions have been presented in many scientific papers, e.g., [4-6]. These papers presents numerical solutions and their approximations used to estimate the $Q$-stress in relation to the $J$-integral, the material characteristics, and the relative crack length $a / W$. Figures 3a) and 3b) compare the $Q=f(J)$ and $Q=f\left(\log \left(J /\left(a \cdot \sigma_{0}\right)\right)\right)$ curves, respectively, for a single-edge notched plate in bending, SEN(B), a centre cracked plate in tension, $\mathrm{CC}(\mathrm{T})$, and a single-edge notched plate in tension, $\mathrm{SEN}(\mathrm{T})$ with a specified geometry for which the $Q$-stress was identified [4-6]. The comparison also includes recent data concerning a double-edge notched plate in tension, $\mathrm{DEN}(\mathrm{T})$. 
a)

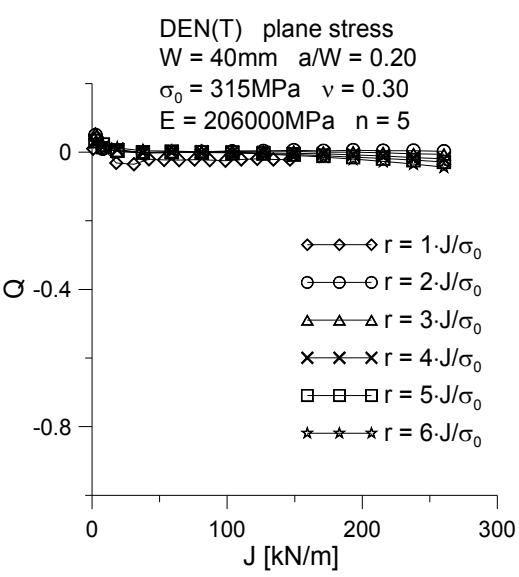

b)

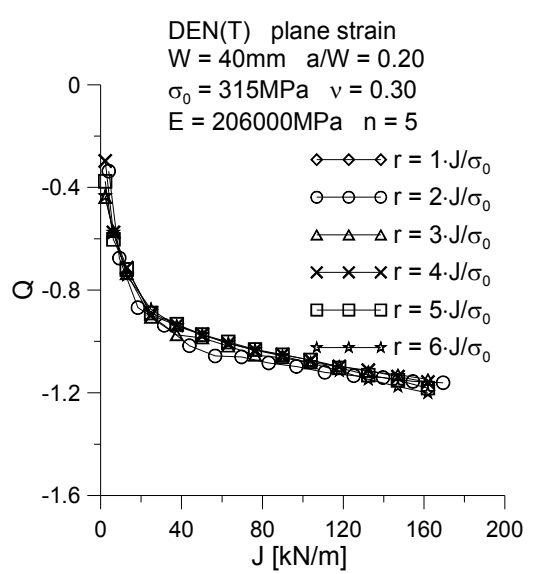

Fig.2. The $J-Q$ trajectories for $\operatorname{DEN}(\mathrm{T})$ specimens in tension under a) plane stress; b) plane strain (with measurements made at six different distances from the crack tip) - based on [4-6].

a)

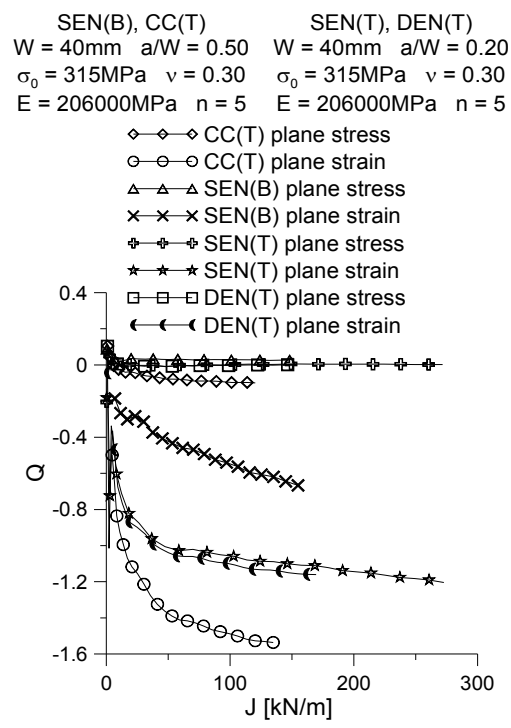

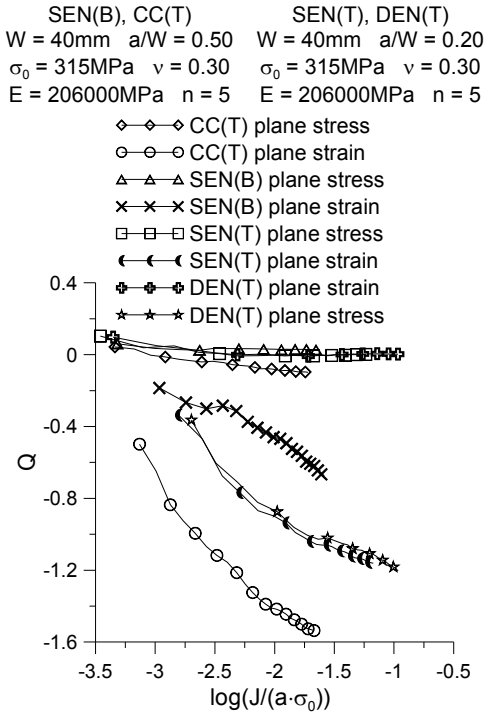

$\begin{array}{cc}\operatorname{SEN}(B), C C(T) & \operatorname{SEN}(T), D E N(T) \\ W=40 \mathrm{~mm} \quad \mathrm{a} / \mathrm{W}=0.50 \quad W=40 \mathrm{~mm} \quad \mathrm{a} / \mathrm{W}=0.20\end{array}$

$\sigma_{0}=315 \mathrm{MPa} \quad v=0.30 \quad \sigma_{0}=315 \mathrm{MPa} \quad v=0.30$

b)

$\log \left(\mathrm{J} /\left(\mathrm{a} \cdot \sigma_{0}\right)\right)$

Fig.3. The comparison of a) the $J-Q$ trajectories and b) the $Q=\mathrm{f}\left(\log \left(J /\left(a \cdot \sigma_{0}\right)\right)\right)$ trajectories for $\mathrm{CC}(\mathrm{T})$, SEN(B), SEN(T), and DEN(T) specimens in plane stress and plane strain (with measurements made at the same distance from the crack tip, $r=2 \cdot J / \sigma_{0}$ ) - based on [4-6]).

\section{Selected fracture criteria based on the Q-stress theory [4-6]}

The O'Dowd and Shih theory $[7,8]$ has been used to formulate the fracture criteria, assess the stress distribution near the crack tip, and solve various engineering problems in the field of elastic-plastic fracture mechanics [4-6]. To apply the O'Dowd and Shih approach, an engineer needs to know only the $Q$-stress (which is calculated numerically) [4-6], the material characteristics, and the element geometry [4-6]. As can be seen from Figure 3, the $Q$-stress is dependent on the geometry and material of the plate. A complete catalog of numerical solutions is required to employ the O'Dowd and Shih theory while solving engineering problems [4-6]. Some types of specimens have already been discussed in the literature [4-6], but there is not much information on the behavior of DEN(T), C(T), SEN(4PB) or CCSP(BT) specimens.

The $J-Q$ theory has been used in various engineering programs, including SINTAP [9] and FITNET [10]. The $Q$-stress is necessary to formulate the fracture criterion and assess the fracture toughness of a structural component [4-6]. Thus, the O'Dowd and Shih theory can be applied to solve many engineering 
problems [4-6]. Some of the formulae used to determine fracture toughness are presented below [4-6]. Using the $J-Q$ theory, O'Dowd [11] proposed the following fracture criterion

$$
J_{C}=J_{I C}\left(1-\frac{Q}{\left(\sigma_{c} / \sigma_{0}\right)}\right)^{n+1}
$$

where $J_{C}$ is the actual fracture toughness of a structural element characterized by a geometrical constraint defined by the $Q$-stress (whose value is usually less than zero), $J_{I C}$ is the fracture toughness of the element in plane strain at $Q=0$, and $\sigma_{c}$ is the critical stress according to the Ritchie-Knott-Rice hypothesis [12], [4-6]. The fracture criterion proposed by O'Dowd and Shih was discussed by Neimitz et al. in [13, 14]. They modified the O'Dowd and Shih formula (Eq.(1.4)) by replacing the critical stress, $\sigma_{c}$, with the maximum crack opening stress, $\sigma_{22} \max$, which is calculated numerically using a large-strain formulation. The formula proposed in $[13,14]$ has the following form [4-6]

$$
J_{C}=J_{I C}\left(1-\frac{Q}{\left(\sigma_{22 \_\max } / \sigma_{0}\right)}\right)^{n+1} .
$$

Neimitz et al. [14] studied the behavior of a single-edge notched plate in bending (SEN(B)) under plane strain conditions. They used a finite element method and a large-strain formulation to estimate the maximum crack opening stress $\sigma_{\max }$ for several materials (differing in the RO exponent and yield stress) and several crack lengths $[14,15]$.

\section{The maximum crack opening stress - $\sigma_{22}$ max $[15-18]$}

The O'Dowd and Shih theory and the fracture criterion expressed by Eq.(1.5) require that the maximum crack opening stress be determined first. In the FEM analysis, the crack opening stress reaches a maximum when strains are finite. In a real structural element with a crack, stresses around the crack tip are finite [16-18]. Figure 4 compares the FEM results obtained for small- and large-strain cases [16-18].
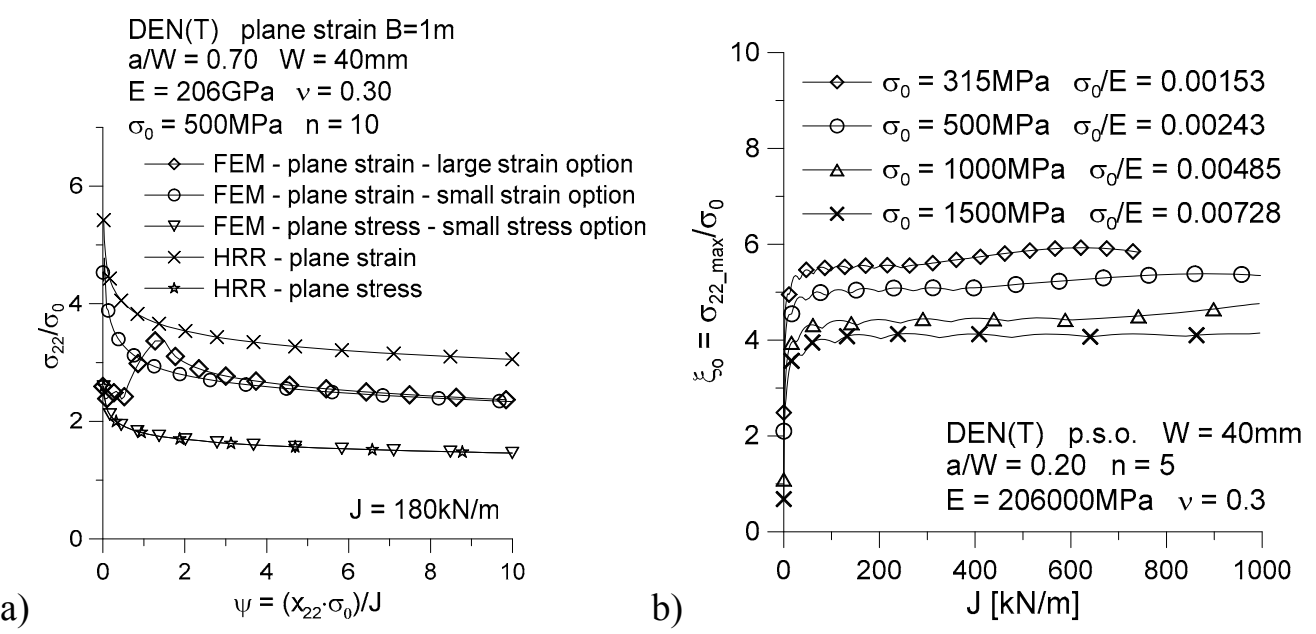

Fig.4. a) The stress distribution near the crack tip for SEN(B) specimens - curves generated through the finite element analysis assuming small and finite strain and the HRR formula (based on [13-18]); b) The influence of the $J$-integral on the maximum crack opening stress (normalized by yield stress) for $\mathrm{DEN}(\mathrm{T})$ plates with a specified geometry differing in yield stress.

The stress infinity problem is a result of the assumption that the crack tip is perfectly sharp and it remains sharp when under load [16-18]. When the large strain is assumed to be relaxed, the crack tip blunts and 
stresses in front of the crack tip become finite. The crack opening stress reaches a maximum at a distance of $r=(0.5$ to 2.0$) \cdot J / \sigma_{0}$, and its value is dependent on the material properties, the specimen geometry, and the external loading [16-18]. The finite element analysis of the stress and strain fields around the crack tip when the finite strains are used is complex in character [16-18]. The level and position of maximum stresses depend on the FE mesh details. It is thus necessary that the mesh be properly selected. This problem is not observed when strain is small. This issue has been discussed in several articles [16-18]. From the numerical analysis it is evident that the maximum crack opening stress depends on the external load, the material properties, and the geometry of the structural element [13-18]. Some numerical results concerning SEN(B) and CC(T) specimens were presented in [13-18]. Other basic geometries presented in the EPRI [19], SINTAP [9] or FITNET [10] procedures have not been analyzed in this respect. Therefore, to simplify engineering analyses, especially those involving evaluation of fracture toughness or description of the stress field near the crack tip in elastic-plastic materials, engineers need catalogs of numerical solutions, where the Q-stress or the maximum crack opening stress for different geometries is provided. This paper includes such catalogs for DEN(T) plates. They will complement the catalogs for SEN(B) and CC(T) specimens published earlier in [14-17].

\section{Engineering application of elastic-plastic fracture mechanics}

The HRR solution presented above [1, 2] was also a basic thesis in the EPRI procedures [19]. The authors of the EPRI procedures [19] provide not only commands that allow us to estimate the strength of structural elements with cracks using failure assessment diagrams (FAD) or crack driving force (CDF) diagrams but also hybrid patterns based on analytical considerations and numerical solutions, which enable estimation of the $J$-integral, the crack tip opening displacement (CTOD), and the load line displacement $v_{L L}$. The main idea for this approach is that engineering analysis does not require performing numerical calculations. The authors of the EPRI procedures [19] suggest that hybrid calculations of the $J$-integral, the crack tip opening displacement, $\delta$, and the load line displacement, $v_{L L}$, be performed using Eqs (1.6)-(1.8) based on the decomposition of the quantity for the elastic and plastic parts

$$
\begin{aligned}
& J=J_{e l}+J_{p l}=J_{e l}+\alpha \cdot \sigma_{0} \cdot \varepsilon_{0} \cdot b \cdot h_{1}\left(\frac{a}{W}, n\right) \cdot\left(\frac{P}{P_{0}}\right)^{n+1}, \\
& \delta=\delta_{e l}+\delta_{p l}=\delta_{e l}+\alpha \cdot \varepsilon_{0} \cdot b \cdot h_{2}\left(\frac{a}{W}, n\right) \cdot\left(\frac{P}{P_{0}}\right)^{n}, \\
& \mathrm{v}_{L L}=\mathrm{v}_{L L_{-} e l}+\mathrm{v}_{L L_{-} p l}=\mathrm{v}_{L L_{-} e l}+\alpha \cdot \varepsilon_{0} \cdot b \cdot h_{3}\left(\frac{a}{W}, n\right) \cdot\left(\frac{P}{P_{0}}\right)^{n}
\end{aligned}
$$

where the subscript ' $e l$ ' denotes the elastic part of the quantity and the subscript ' $p l$ ' refers to the plastic part of the quantity; $b$ is the uncracked ligament of the specimen $(b=W-a) ; h_{1}, h_{2}, h_{3}$ are the functions determined numerically by the EPRI authors [19] and presented in the EPRI procedures [18] for different geometries, different relative crack lengths, and different strain hardening exponents, $n$ (exemplary values of the functions $h_{l}$ and $h_{3}$ for DEN(T) plates provided in Tab.1); $P$ is the external load and $P_{0}$ is the limit load, which can be calculated for $\operatorname{DEN}(\mathrm{T})$ plates using the following formulae [19]

$$
\begin{aligned}
& P_{0}=\frac{4}{\sqrt{3}} \cdot b \cdot \sigma_{0} \quad \text { for plane stress, } \\
& P_{0}=\left(0.72+1.82 \cdot \frac{b}{W}\right) \cdot W \cdot \sigma_{0} \quad \text { for plane strain }
\end{aligned}
$$

where $W$ is the width of the specimen (plate). 
Table 1. The values of the functions $h_{1}$ and $h_{3}$ for $\operatorname{DEN}(\mathrm{T})$ plates in plane strain (based on the EPRI procedures [19]).

\begin{tabular}{|c|c|c|c|c|c|c|c|c|c|}
\hline \multicolumn{9}{|c|}{$h_{1}$} & \multicolumn{5}{|c|}{$h_{3}$} \\
\hline$a / W$ & $n=3$ & $n=5$ & $n=10$ & $n=20$ & $a / W$ & $n=3$ & $n=5$ & $n=10$ & $n=20$ \\
\hline 0.125 & 0.922 & 1.13 & 1.61 & 2.44 & 0.125 & 0.20 & 0.372 & 0.911 & 2.29 \\
\hline 0.250 & 1.38 & 1.65 & 1.82 & 1.92 & 0.250 & 0.698 & 1.11 & 1.92 & 2.73 \\
\hline 0.375 & 1.92 & 1.92 & 1.68 & 1.12 & 0.375 & 1.40 & 1.87 & 2.20 & 1.67 \\
\hline 0.500 & 2.48 & 2.43 & 2.12 & 1.51 & 0.500 & 2.37 & 2.79 & 2.68 & 1.94 \\
\hline 0.625 & 3.45 & 3.42 & 3.00 & 2.27 & 0.625 & 3.74 & 3.9 & 3.23 & 2.19 \\
\hline 0.750 & 7.17 & 8.44 & 10.90 & 17.40 & 0.750 & 7.03 & 7.63 & 9.04 & 13.50 \\
\hline 0.875 & 39.00 & 78.40 & 341.00 & 3820.00 & 0.875 & 24.10 & 40.40 & 149.00 & 1560.00 \\
\hline
\end{tabular}

The numerical calculations presented in [20-21] and [31] show that the formulae given in the EPRI procedures [19] are not always exact and the results obtained with them differ from those obtained through the finite element analysis. Some of the differences were discussed in [21], where the authors verified the limit load solutions for SEN(T) specimens. Another example is Ref. [20], where an analysis of hybrid solutions is performed to estimate the values of the $J$-integral for SEN(B) specimens using the EPRI procedures [19]. The author indicated the differences between the numerical solution and the EPRI solution [19] and proposed a slightly different approach, omitting the decomposition of the $J$-integral for the elastic and plastic parts.
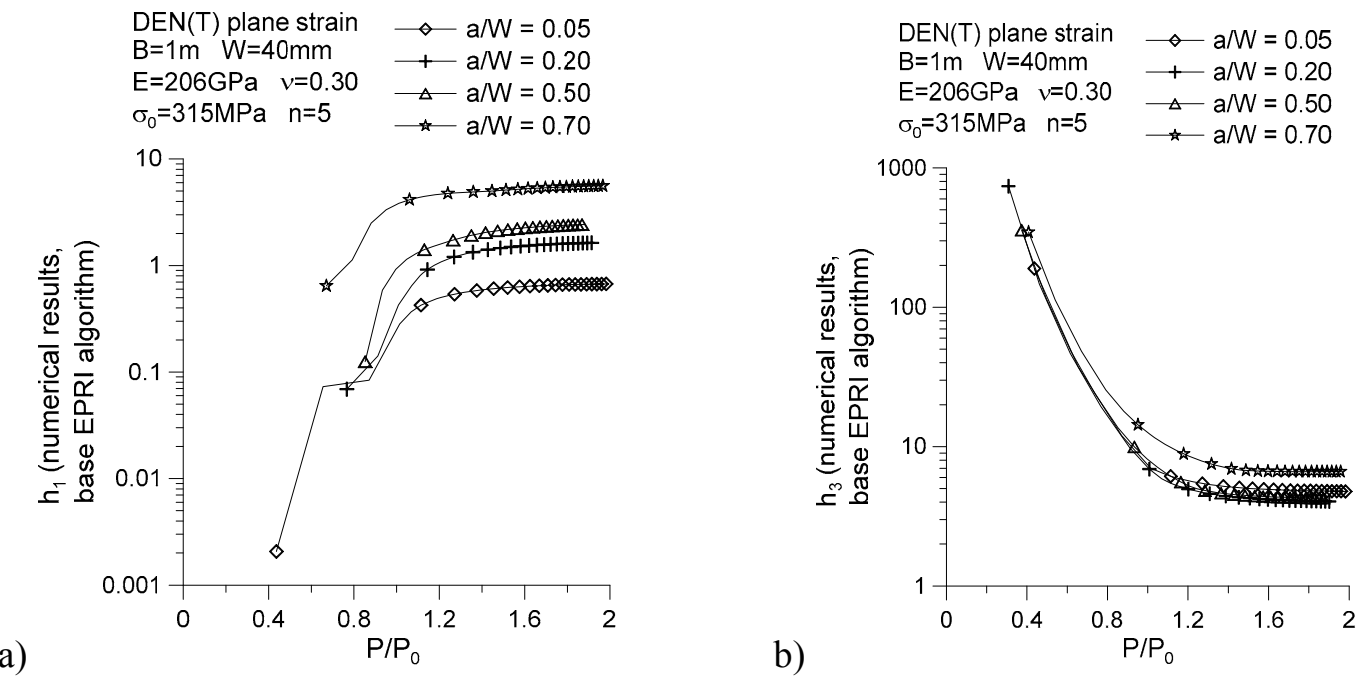

Fig.5. The values of the functions $h_{1}$ and $h_{3}$ for DEN(T) plates obtained through numerical calculations using the EPRI algorithm (the approximate values of the function $h_{1}$ for the saturation level: $a / W=0.05, h_{l}=0.67 ; a / W=0.20, h_{l}=1.63 ; a / W=0.50, h_{l}=2.40 ; a / W=0.70, h_{l}=5.60 ;$ the approximate values of the function $h_{3}$ for the saturation level: $a / W=0.05, h_{3}=4.8 ; a / W=0.20, h_{3}=4.05 ; a / W=0.50$, $\left.h_{3}=4.30 ; a / W=0.70, h_{3}=6.62\right)$.

The EPRI procedures [19] show that for the DEN(T) type of plate and the configuration of materials listed above, the values of the functions $h_{1}, h_{2}$ and $h_{3}$ should be constant at any level of external loading. The numerical calculations carried out by the author of this paper point to the fact that the values of these functions change with external load, particularly in the range $P / P_{0}=\langle 0 ; 0.5 \div 0.7\rangle$, where the changes are clear. Then, an increase in external load causes the functions to reach saturation (see Fig.5 for $h_{l}$ and $h_{3}$ functions).

The saturation of the functions $h_{1}$ and $h_{3}$ (Fig.5) differs from that achieved according to the EPRI procedures [19] (see Tab.1). It is thus necessary to verify the solutions proposed in 1981 [19] and this requires intensive numerical analysis. This paper will verify the solutions given in the EPRI procedures [1] and the verification will include calculations of the limit loads for DEN(T) plates in plane stress and plane 
strain. The paper will also review the formulae to estimate the $J$-integral, crack tip opening displacement and the load line displacement for plane strain. The choice of plane strain is not accidental - a plane strain state is required to experimentally determine fracture toughness under laboratory conditions. Finally, the paper will present a broad catalog of ready-to-use numerical solutions for selected configurations of material properties and geometric characteristics of the $\operatorname{DEN}(\mathrm{T})$ plate to estimate the limit loads, the $Q$-stress, the maximum crack opening stress, the $J$-integral, the crack tip opening displacement, and the load line displacement as a function of the normalized external load, with no need for FEM calculations. All the numerical results presented here can be used in engineering analysis.

\section{Details of the numerical calculations (based on [4-6, 15-18])}

The numerical analysis was conducted for $\mathrm{DEN}(\mathrm{T})$ specimens with the width $W=40 \mathrm{~mm}$ and the length $L$ satisfying the condition that $L \geq 2 W$ (see Fig.6a). As different relative crack lengths were considered, i.e., $a / W=\{0.05,0.20,0.50,0.70\}$, different levels of 'in-plane' constraints were obtained. That affected the fracture toughness, the stress distribution near the crack tip, the $Q$-stress, and the maximum crack opening stress [15]. The total length of the plate under study was $L=176 \mathrm{~mm}$. The plane strain analysis was carried out according to the ADINA recommendations [22, 23] for specimens with a thickness of $B=1 \mathrm{~m}$ or $B=1 \mathrm{~mm}$ under plane stress. The analysis of the state of plane stress involved determining only the limit loads.
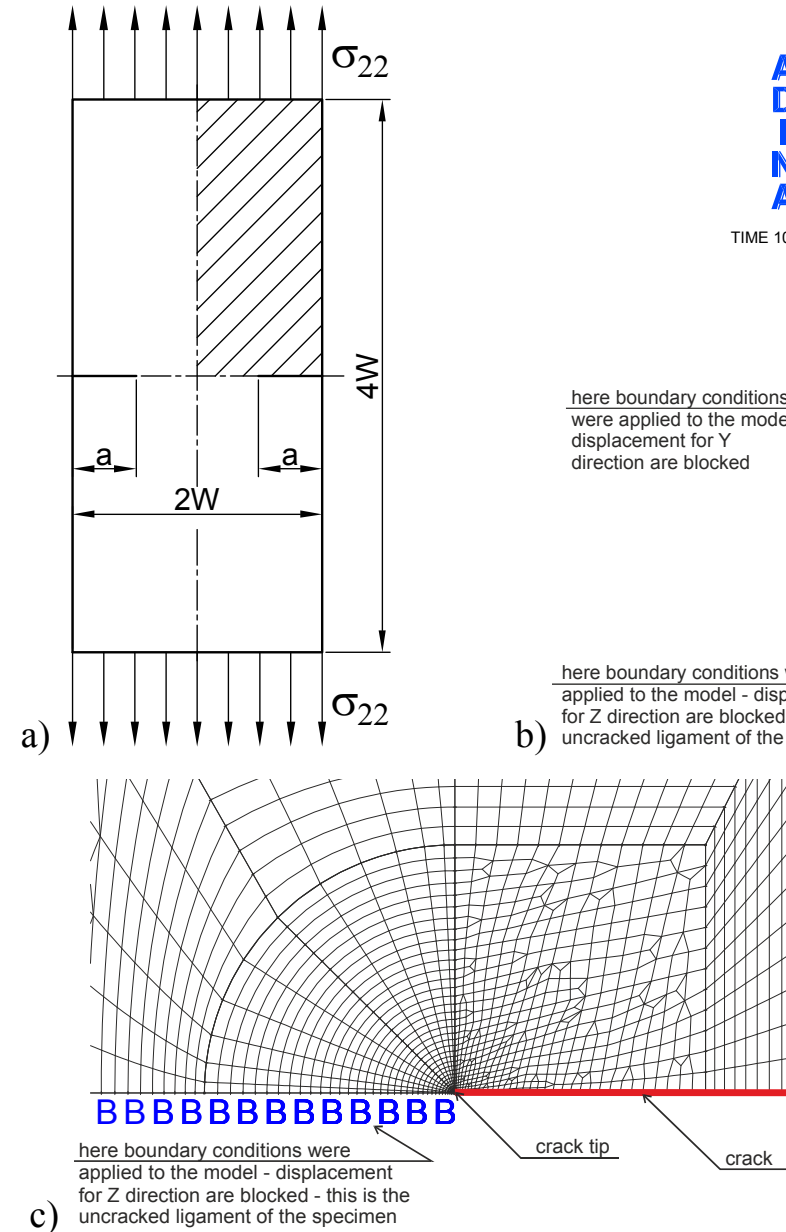

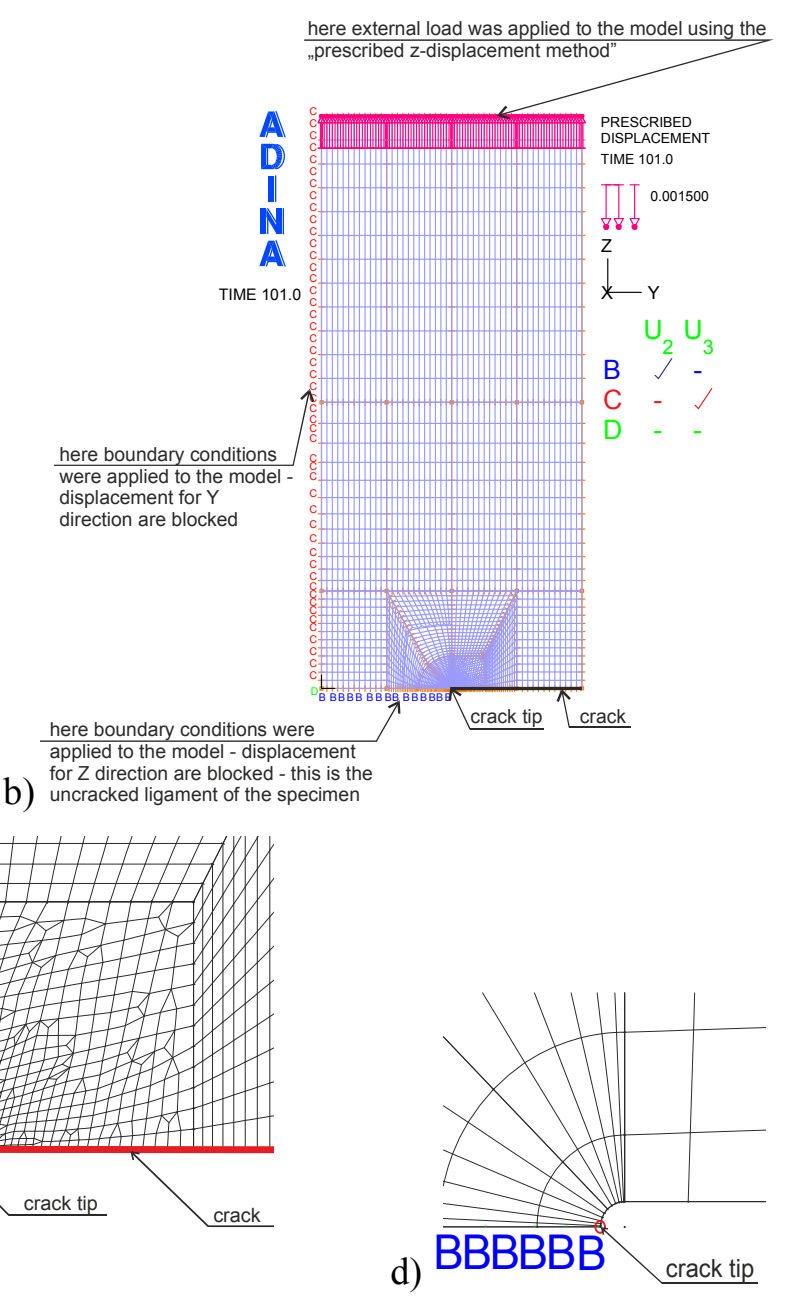

d)

Fig.6. a)The DEN(T) specimen with a hatched region modeled using the FEM; b) A finite element model of a quarter of the $\operatorname{DEN}(\mathrm{T})$ plate; c) The finite element mesh of the region near the crack tip; d) A model of the crack tip with finite elements used in the FEM calculations. 
The model of the elastic-plastic material was used to determine the $Q$-stress, the maximum crack opening stress, the $J$-integral, the CTOD or the load line displacement. Young's modulus was $E=206 \mathrm{GPa}$ and Poisson's ratio was $v=0.30$. Four values of the yield stress and four values of the strain hardening exponent were analyzed: $\sigma_{0}=\{315,500,1000,1500\} \mathrm{MPa}$ and $n=\{3.36,5,10,20\}$, respectively [4-6, 15-17]. The wide range of properties considered in the numerical analysis of the model materials correspond to the characteristics of ferritic steels, structural steels and high strength steels [15]. In the FEM simulations, the elastic-plastic material was modeled using the deformation theory of plasticity and the modified von Misses yield criterion. In the model, the stress-strain curve was approximated as follows

$$
\frac{\varepsilon}{\varepsilon_{0}}= \begin{cases}\sigma / \sigma_{0} & \text { for } \sigma \leq \sigma_{0} \\ \alpha\left(\sigma / \sigma_{0}\right)^{n} & \text { for } \sigma>\sigma_{0}\end{cases}
$$

where $\alpha=1$.

The limit load was calculated for an elastic-perfectly plastic material [21].

The choice of the DEN(T) specimen was intentional because DEN(T) specimens are used in the FITNET procedures [10] to model real structural elements. In the FITNET [10] or SINTAP procedures [9], there are no solutions to determine the limit loads or the stress intensity factors for DEN(T) specimens. In the EPRI procedures [19], a hybrid method is given to calculate the $J$-integral, the CTOD, and the load line displacement. However, the limit load solutions provided in the EPRI [19] are different from the FEM results [21]. The critical values of the $J$-integral can also be determined through the laboratory testing of DEN(T) specimens [24].

All the numerical computations were performed using the ADINA SYSTEM 8.8 [22,23]. Because of the specimen symmetry, only a quarter was modeled (see Fig.6a). All the calculations were conducted for the state of plane strain [4-6, 15-17]. The finite element mesh was filled with nine-node plane strain FEs with mixed formulation of interpolation [4-6] (each finite element had nine points of numerical integration) [4-6]. Small strain and small displacement were assumed to calculate the $Q$-stress, the $J$-integral, the crack tip opening displacement, and the load line displacement [4-6]. New hybrid formulae were proposed for these three parameters. The maximum crack opening stress was determined assuming that the strain and the displacement were large [15-17].

The size of the finite elements in the radial direction decreased towards the crack tip, while the size of the elements in the angular direction was constant. The crack tip region was modeled using $36 \div 50$ semicircles [4-6, 15-17]. The first of them was at least $20 \div 50$ times smaller than the last one. This means that the first finite element behind the crack tip was smaller $3076 \div 10210$ times than the width of the specimen. The crack tip was modeled as a quarter of an arc with the radius $r_{w}=(1 \div 5) \cdot 10^{-6} \mathrm{~m}$, i.e., $(1 / 40000 \div 1 / 800) \times W[4-$ $6,15-17]$. The whole DEN(T) specimen was modeled using $3149 \div 3428$ finite elements and $12803 \div 13921$ nodes. External load was applied to the bottom edge of the specimen. Figure 6 presents the numerical model used in the numerical calculations. The model was built according to the literature (see Brocks et al. [25-26] and Graba and Gałkiewicz [18]). It should be noted that the same numerical model of the specimen was used to determine the limit loads and calculate the stress distribution for small and large strains.

In the numerical analysis of an elastic-plastic material, the $J$-integral was calculated with the "virtual shift method", which uses the virtual crack growth concept to compute the virtual energy change [22, 23]. In the analysis, eight contours were considered. They covered the crack tip area with a radius of 10, 15, 20, 25, $30,35,40$ or 45 finite elements near the crack tip; the results obtained for each of the contours were convergent [15, 18, 25-26].

The crack tip opening displacement (CTOD), denoted also as $\delta_{T}$, was determined in accordance with the method proposed by Shih [27]. The diagram for the determining the CTOD, $\delta_{T}$, is given in Fig.7. The CTOD was calculated through numerical analysis for an elastic-plastic material, in the same way as the load line displacement. 


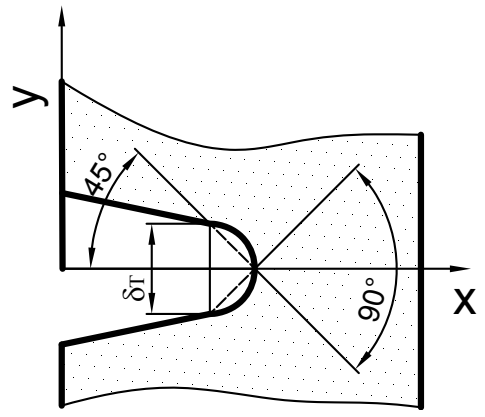

Fig.7. The concept of Shih's proposal [27] to determine the crack tip opening displacement (CTOD), denoted also as $\delta_{T}$.

Plane stress was calculated using numerical analysis for an elastic-perfectly plastic material, which is required to determine the limit loads. At this stage, the same numerical model was used. Only 9-node plane stress finite elements with default formulation of interpolation were used.

To summarize, the limits loads were determined numerically using $32 \mathrm{DEN}(\mathrm{T})$ specimens under plane stress or plane strain, which differed in the crack length (different $a / W$ ) and the yield stress. This calculations were made with the assumption of an elastic-perfectly plastic material. In the analysis for an elastic-plastic material, $64 \mathrm{DEN}(\mathrm{T})$ specimens were used to calculate the $Q$-stress and the basic fracture parameters $\left(J\right.$-integral, CTOD, $\mathrm{v}_{L L}$ ), assuming that strain was small [4-6]. Other $64 \mathrm{DEN}(\mathrm{T})$ specimens were used to calculate the maximum crack opening stresses and their position near the crack tip [15-17].

\section{Numerical results}

\section{Limit load for plane strain and plane stress}

The first step of the analysis was to estimate the limit loads. The numerical estimation of the limit loads was based on the results of the observations of the increasing plastic zone and the graphs presenting external load versus load line displacement. The determined values of the limit loads were compared with the values determined using "the twice elastic slope method". The values of the limit load obtained for plane stress and plane strain are presented in Tab.2.

Table 2. Numerically estimated limit load for DEN(T) specimens under plane stress and plane strain.

\begin{tabular}{|c|c|c|c|c|c|c|c|c|}
\hline & \multicolumn{3}{|c|}{ plane stress $(B=1 \mathrm{~mm})$} & \multicolumn{3}{c|}{ plane strain $(B=1 \mathrm{~m})$} \\
\hline $\begin{array}{c}\sigma_{0} \\
{[\mathrm{MPa}]}\end{array}$ & $a / W=0.05$ & $a / W=0.20$ & $a / W=0.50$ & $a / W=0.70$ & $a / W=0.05$ & $a / W=0.20$ & $a / W=0.50$ & $a / W=0.70$ \\
\hline & $P_{0}[\mathrm{kN}]$ & $P_{0}[\mathrm{kN}]$ & $P_{0}[\mathrm{kN}]$ & $P_{0}[\mathrm{kN}]$ & $P_{0}[\mathrm{kN}]$ & $P_{0}[\mathrm{kN}]$ & $P_{0}[\mathrm{kN}]$ & $P_{0}[\mathrm{kN}]$ \\
\hline 315 & 24.70 & 22.35 & 14.37 & 8.55 & 28563.97 & 26083.73 & 20311.97 & 15211.66 \\
\hline 500 & 39.18 & 35.45 & 22.81 & 13.57 & 45335.93 & 41398.11 & 32233.58 & 24149.73 \\
\hline 1000 & 78.19 & 69.58 & 45.62 & 27.14 & 90672.02 & 82796.32 & 64467.13 & 48185.29 \\
\hline 1500 & 117.45 & 106.11 & 68.44 & 40.71 & 135979.90 & 124159.80 & 96642.58 & 72370.87 \\
\hline
\end{tabular}

Figure 8 shows the influence of the relative crack length and the yield stress on the limit load. From the numerical results it is clear that if the same value of the specimen thickness is the reference value, the values of the limit load for plane strain are greater than those for plane stress. Greater values of the limit load are observed at higher values of the yield stress. An increase in the crack length causes a decrease in the value of the limit load. All the above conclusions are natural. The analysis of the numerical results indicates proportional dependence of the limit load on the yield stress, which can be observed in Fig. $8 \mathrm{~b}$. The 
relationship between the limit load, $P_{0}$, and the relative crack length, $a / W$, for DEN(T) plates is nonlinear, especially for plates with very short and short cracks, $a / W=0.05$ and $a / W=0.20$, respectively, (see Fig.8a).

a)

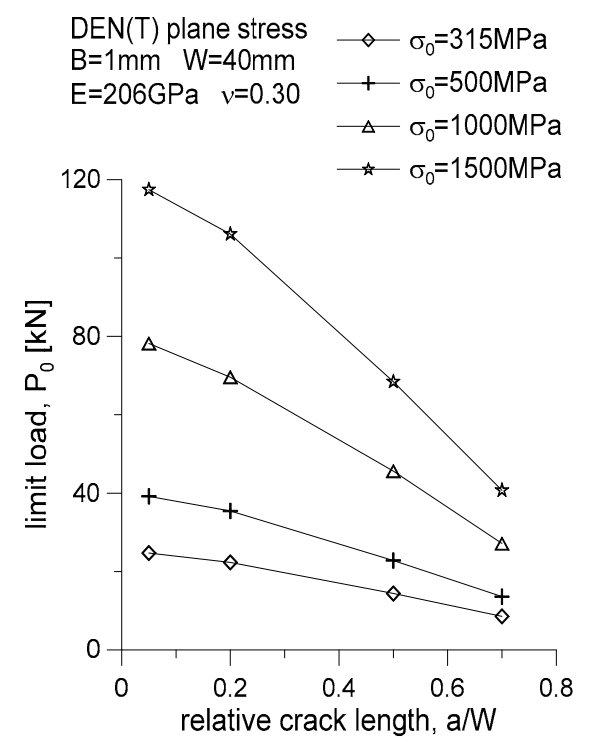

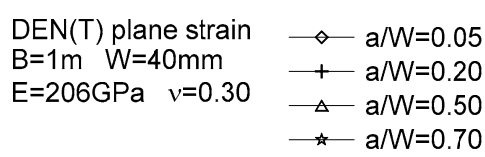

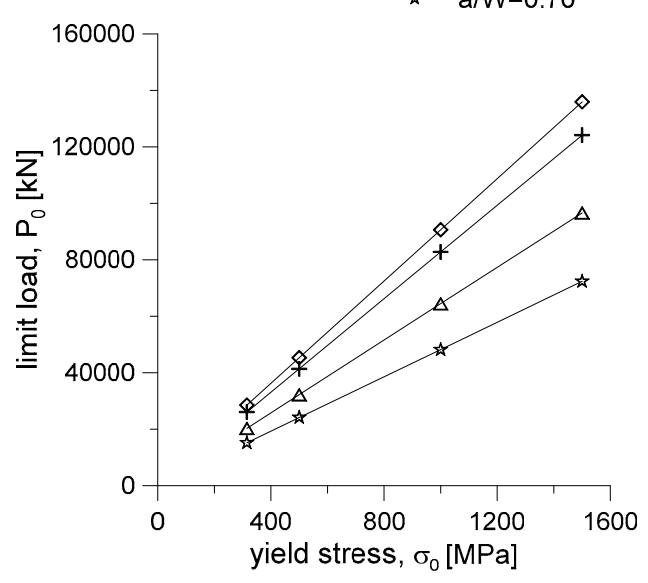

Fig.8. The influence of the yield stress $\sigma_{0}$ (a) and the relative crack length $a / W(\mathrm{~b})$ on the limit load $P_{0}$ for $\mathrm{DEN}(\mathrm{T})$ specimens under plane stress (a) and plane strain (b).

The numerical results of the limit load were compared with the values determined using Equations (5) and (6) for plane stress and plane strain, respectively [19]. Table 3 shows the differences between the numerical solutions and the EPRI results [19], which were obtained as $\left(\left(P_{0_{-} F E M}-P_{0_{-} E P R I}\right) / P_{0_{-} E P R I}\right) \cdot 100 \%$ where $P_{0_{-} E P R I}$ is the value of the limit load calculated using Eqs (1.9) or (1.10) (for plane stress or plane strain, respectively), and $P_{O_{-} F E M}$ is the limit load determined by the Finite Element Method (FEM).

Table 3. The difference between the EPRI solutions [1] and the numerical results of the limit load for $\mathrm{DEN}(\mathrm{T})$ specimens in plane stress and plane strain.

\begin{tabular}{|c|c|c|c|c|c|c|c|c|}
\hline & \multicolumn{4}{|c|}{ plane stress $(B=1 \mathrm{~mm})$} & \multicolumn{4}{c|}{ plane strain $(B=1 \mathrm{~m})$} \\
\hline \multirow{2}{*}{$\begin{array}{c}\sigma_{0} \\
{[\mathrm{MPa}]}\end{array}$} & $a / W=0.05$ & $a / W=0.20$ & $a / W=0.50$ & $a / W=0.70$ & $a / W=0.05$ & $a / W=0.20$ & $a / W=0.50$ & $a / W=0.70$ \\
\cline { 2 - 9 } & \multicolumn{3}{|c|}{$\left(\left(P_{0_{-} F E M}-P_{0_{-} E P R I}\right) / P_{0_{-} E P R I}\right) \cdot 100 \%$} & \multicolumn{3}{c|}{$\left(\left(P_{0_{-} F E M}-P_{0_{-} E P R I}\right) / P_{0_{-} E P R I}\right) \cdot 100 \%$} \\
\hline 315 & $-10.65 \%$ & $-4.00 \%$ & $-1.20 \%$ & $-2.05 \%$ & $-7.43 \%$ & $-4.87 \%$ & $-1.10 \%$ & $-4.64 \%$ \\
\hline 500 & $-10.70 \%$ & $-4.07 \%$ & $-1.21 \%$ & $-2.06 \%$ & $-7.44 \%$ & $-4.88 \%$ & $-1.12 \%$ & $-4.62 \%$ \\
\hline 1000 & $-10.90 \%$ & $-5.85 \%$ & $-1.22 \%$ & $-2.07 \%$ & $-7.44 \%$ & $-4.88 \%$ & $-1.12 \%$ & $-4.85 \%$ \\
\hline 1500 & $-10.78 \%$ & $-4.27 \%$ & $-1.22 \%$ & $-2.08 \%$ & $-7.46 \%$ & $-4.90 \%$ & $-1.18 \%$ & $-4.73 \%$ \\
\hline
\end{tabular}

As can be seen, the difference between the numerical solution and the EPRI solution [19] obtained for very short cracks $(a / W=0.05)$ is the greatest; it is nearly $11 \%$ in the case of plane stress and $7 \%$ in the case of plane strain. An increase in the crack length leads to a decrease in the difference between the numerical solution and the EPRI solution [19]. For plates with a relative crack length $(a / W=0.50)$, the difference is about $1.2 \%$. An increase in the crack length $(a / W=0.70)$ causes an increase in the difference between the numerical solution and the EPRI solution [19] to nearly 5\%. It should be noted that the values of the limit load obtained with the EPRI solution are greater than those estimated numerically, as shown in this paper. The average difference is $5 \%$. 


\section{Q-stress}

The values of the $Q$-stress were calculated for elastic-plastic materials using small strain and small displacement assuming the state of plane strain. All the numerical results were calculated for six different distances from the crack tip: $r=\{1,2,3,4,5,6\} \cdot J / \sigma_{0}$ [4-6]. The numerical analysis shows that the $Q$-stress decreases with increasing distance from the crack tip (see Fig.8). It can be noted that the $Q$-stress decreases when the external load increases; in this paper the external load is expressed by the $J$-integral [4-6]. An increase in the external load causes an increase in the difference between the $Q$-stress calculated at the selected measurement points (see Fig.8) [4-6].
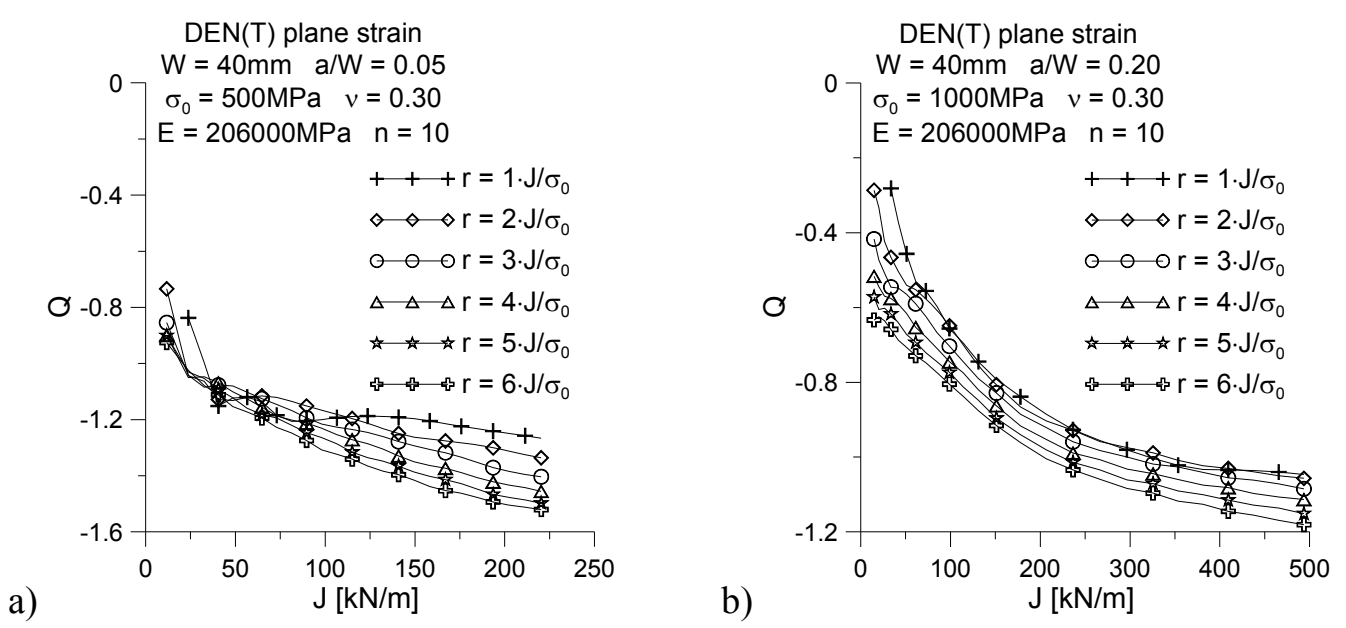

Fig.9. The ' $J-Q$ family curves' for $\mathrm{DEN}(\mathrm{T})$ specimens calculated at six different distances $r$ : a) $\mathrm{DEN}(\mathrm{T})$, $\left.a / W=0.05, \sigma_{0}=500 \mathrm{MPa}, n=10 ; \mathrm{b}\right) \mathrm{DEN}(\mathrm{T}), a / W=0.20, \sigma_{0}=1000 \mathrm{MPa}, n=10$.

For an engineer who deals with the evaluation of the fracture toughness and strength of a cracked structure, the most interesting results should be those obtained for the distance $r=2.0 \cdot \mathrm{J} / \sigma_{0}$. The values of the $Q$-stress calculated at this point are used in the fracture criteria presented above (Eqs (1.4) or (1.5)) [4-6]. At this point, the maximum crack opening stress is often observed [15-17]. The analysis of the numerical results for the $Q$-stress at the distance $r=2.0 \cdot J / \sigma_{0}$ should include the influence of the relative crack length, the yield stress, and the strain hardening exponent (see Figs 10-12) [4-6].

Figure 10 shows that the $Q$-stress reaches a more negative value for the same level of the $J$-integral if the crack length decreases. The $Q$-stress drops more rapidly for short cracks than for long ones in the range of small external loads (Fig.10). The $Q$-parameter decreases if the yield stress increases - this conclusion refers to all the $\operatorname{DEN}(\mathrm{T})$ specimen that were used in the research project (Figs 11). Comparing the $J-Q$ trajectories for different values of the ratio $\sigma_{0} / E$, we can see that the biggest differences are observed for materials with a small strain hardening exponent ( $n=3$ - strongly hardening materials) and the smallest for materials characterized by a large strain hardening exponent ( $n=20$ - weakly hardening materials). The analysis of all the results leads to the conclusion that the larger the crack length, the larger the differences (see Annexes A-D). It can be noted that for smaller yield stress, the $J$ - $Q$ trajectories lie lower and the changes in the $Q$-parameter are more rapid when the external load increases (see Fig.11) [4-6]. 


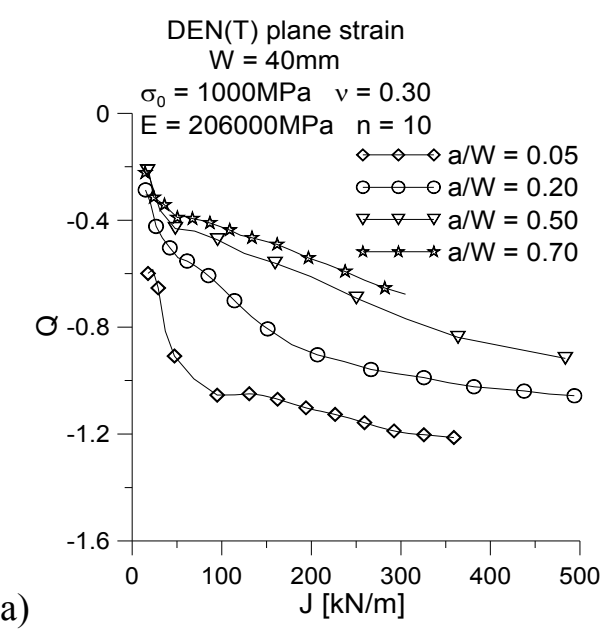

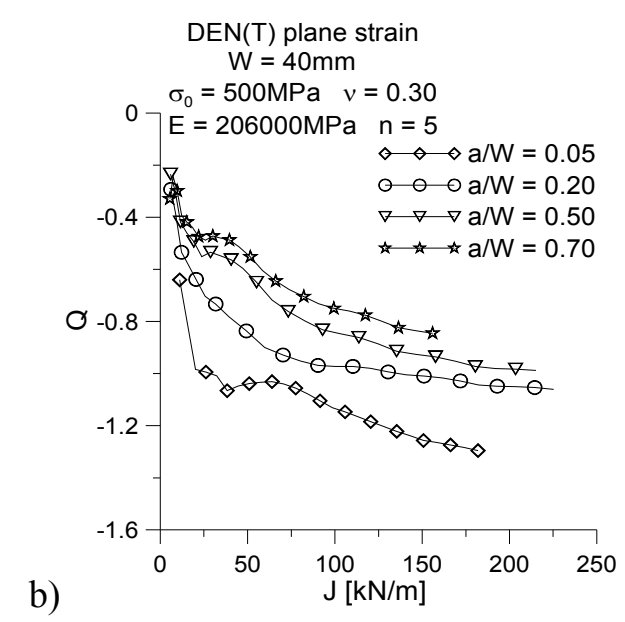

Fig.10. The influence of the crack length on the $J-Q$ trajectories for $\operatorname{DEN}(\mathrm{T})$ specimens: a) $\operatorname{DEN}(\mathrm{T})$, $\sigma_{0}=1000 \mathrm{MPa}, n=10$; b) DEN(T), $\sigma_{0}=500 \mathrm{MPa}, n=5$ (results for the distance $r=2 \cdot \mathrm{J} / \sigma_{0}$ ).
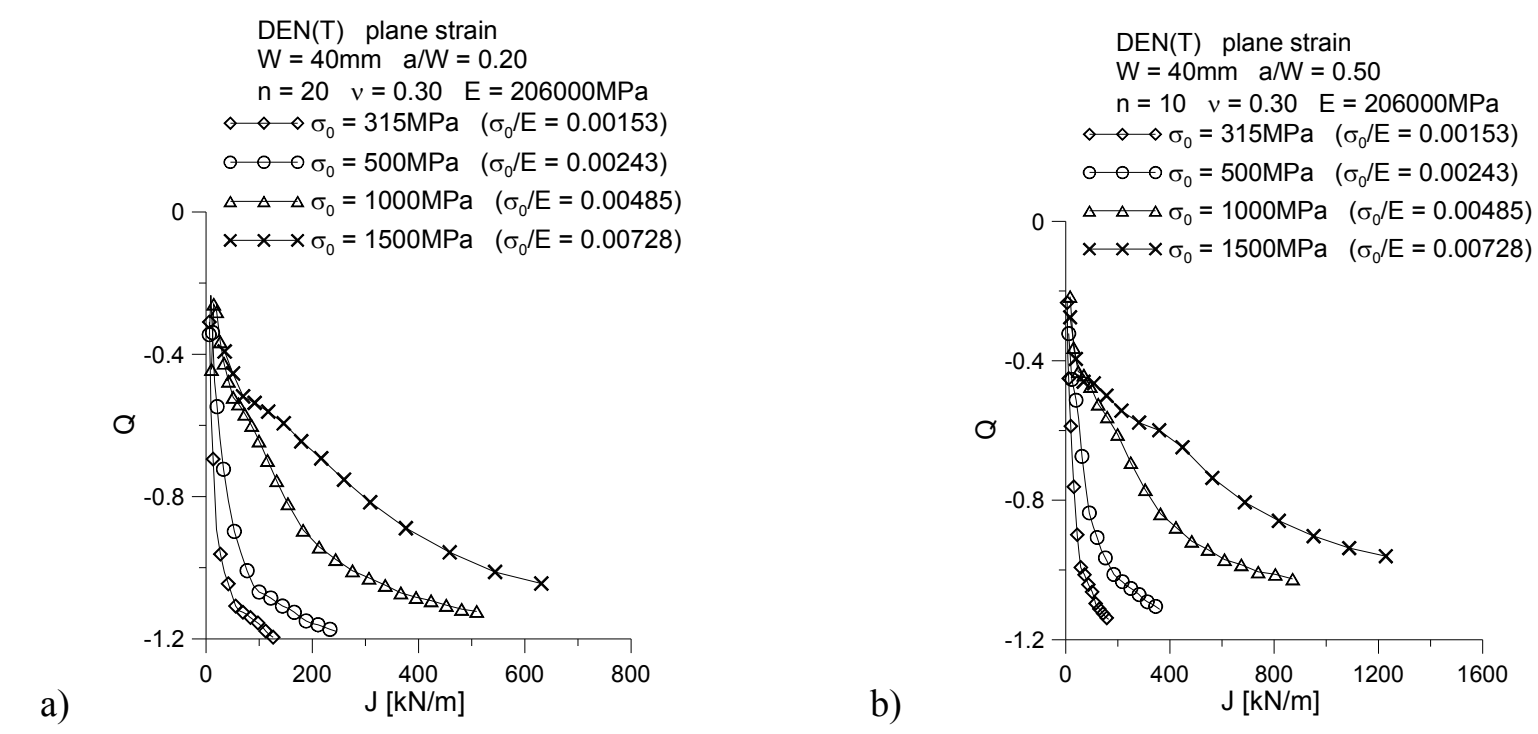

Fig.11. The influence of the yield stress on the $J-Q$ trajectories for $\operatorname{DEN}(\mathrm{T})$ specimens: a) $\operatorname{DEN}(\mathrm{T})$, $a / W=0.20, n=20 ; \mathrm{b}$ ) DEN(T), $a / W=0.50, n=10$ (results for the distance $r=2 \cdot J / \sigma_{0}$ ).

The influence of the strain hardening exponent on the $J-Q$ trajectories seems quite interesting. For the analyzed geometry, i.e., $\mathrm{DEN}(\mathrm{T})$ plates, it is clear that when the strain hardening exponent increases, the $Q$-stress decreases; the exception is the specimens with the relative crack length $a / W=0.70$ (see Fig.12d). For strongly hardening materials, the values of the $Q$-stress are higher. The cutting of the $J-Q$ trajectories is observed (Fig.12d) for the specimens with long cracks $(a / W=0.70)$. First, higher values of the $Q$-stress are reported for the specimens made of a weakly hardening material, but when there is an increase in external load, the trend changes and higher values of the $Q$-stress are observed for the specimens made of a strongly hardening material (Fig.12d) [4-6]. 
a)

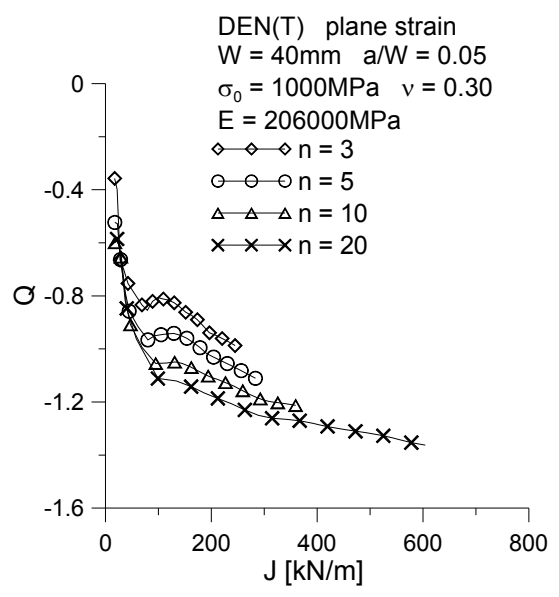

c)

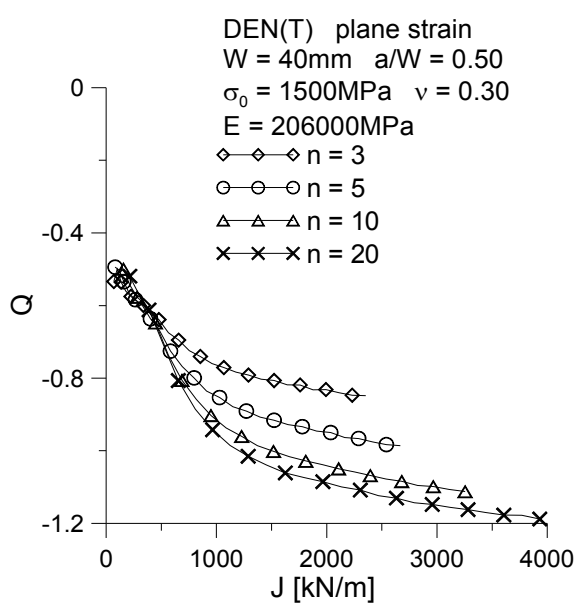

b)

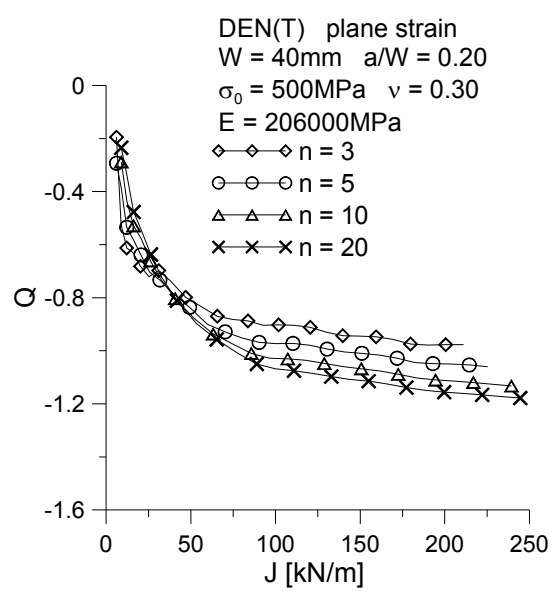

d)

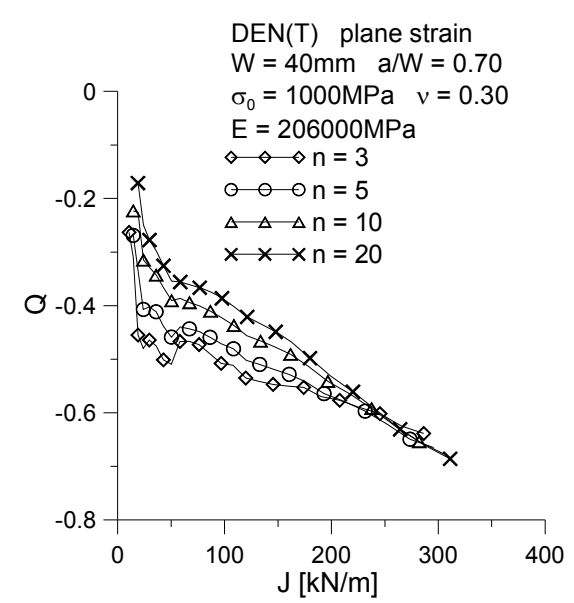

Fig.12. The influence of the strain hardening exponent on the $J-Q$ trajectories for $\operatorname{DEN}(\mathrm{T})$ specimens: a) $\operatorname{DEN}(\mathrm{T}), a / W=0.05, \sigma_{0}=1000 \mathrm{MPa}$; b) $\left.\mathrm{DEN}(\mathrm{T}), a / W=0.20, \sigma_{0}=500 \mathrm{MPa} ; \mathrm{c}\right) \operatorname{DEN}(\mathrm{T}), a / W=0.50$, $\left.\sigma_{0}=1500 \mathrm{MPa} ; \mathrm{d}\right) \operatorname{DEN}(\mathrm{T}), a / W=0.70, \sigma_{0}=1000 \mathrm{MPa}$ (results for the distance $r=2 \cdot \mathrm{J} / \sigma_{0}$ ).

At this point, it is worth noting that for the specimens with long cracks $(a / W=0.70)$, the $J-Q$ trajectories were different in nature from those obtained for the specimens with the relative crack length $a / W \leq 0.50$ (see Figs 10 and 12). This problem was discussed by Chao [28], who stated that it could be due to the fact that the bending stress near the crack tip was not taken into consideration in the analysis of the stress field [4-6].

\section{The maximum crack opening stress and its position near the crack tip}

The maximum crack opening stress is treated as a measure of in-plane constraints - limitations imposed by a material undergoing plastic deformation when subjected to external loading [30]. This parameter - the maximum crack opening stress - is necessary to calculate the actual fracture toughness assuming an appropriate fracture criterion [13-14, 15-17].

The analysis of the results will be conducted in order to evaluate the influence of the material properties and the relative crack length [15-17]. Figure 14 presents the influence of the strain hardening exponent on the $\xi_{o}=\xi_{o}(J)$ trajectories, where $\xi_{o}=\sigma_{22}$ max $/ \sigma_{0}$. For a material characterized by a lower value of the strain hardening exponent, the $\xi_{o}=\xi_{o}(J)$ trajectories lie higher [15-17]. Higher values of the maximum crack opening stress are observed for strongly hardening materials. For the $\xi_{o}=\xi_{o}(J)$ trajectories, the level of saturation was achieved, as discussed in [13-17]. For weakly hardening materials, the level of saturation of 
the $\xi_{o}=\xi_{o}(J)$ trajectories is achieved earlier than for strongly hardening materials. For very strongly hardening materials $(n=3.36)$, an increase in the external load (expressed by the level of the $J$-integral) causes the maximum crack opening stress to increase nonlinearly [15-17].

a)
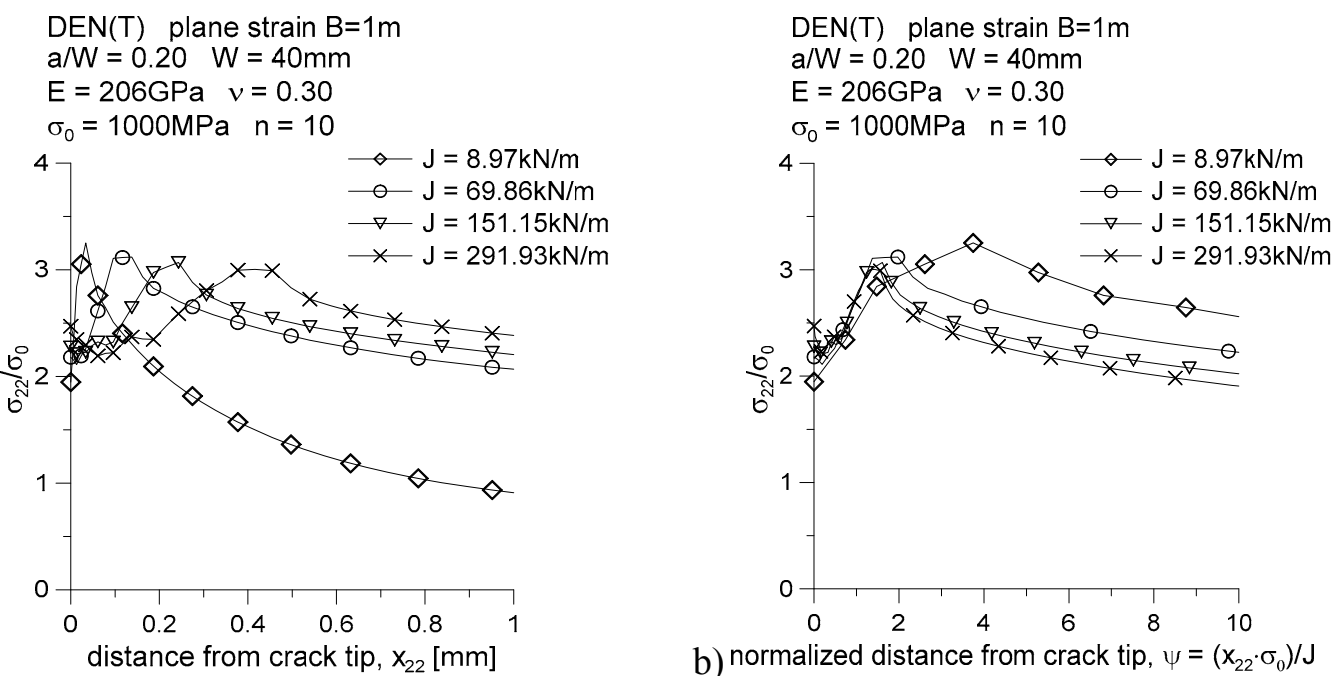

Fig.13. The comparison of the crack opening stress distributions for selected DEN(T) plates at different levels of load expressed by the $J$-integral: a) graph for the physical coordinates near the crack tip $\left.x_{22}[\mathrm{~mm}] ; \mathrm{b}\right)$ graph for the normalized distance from the crack tip $-\psi=\left(x_{22} \cdot \sigma_{0}\right) / J$.

Figure 15 shows the influence of the yield stress on the $\xi_{o}=\xi_{o}(J)$ trajectories. The graphs were generated on the basis of the results obtained for strongly and very weakly hardening materials [15-17]. When the material is characterized by higher values of the yield stress, the $\xi_{o}=\xi_{o}(J)$ trajectories lie lower. The influence of the yield stress was analyzed for very strongly and strongly hardening materials with the strain hardening exponent $n=3.36$ and $n=5$, respectively (Fig.15a) [15-17]. The level of the maximum crack opening stress does not depend on the yield stress when the strain hardening exponent $n$ is $n=10$ and $n=20$ (Fig. 15b).

a)

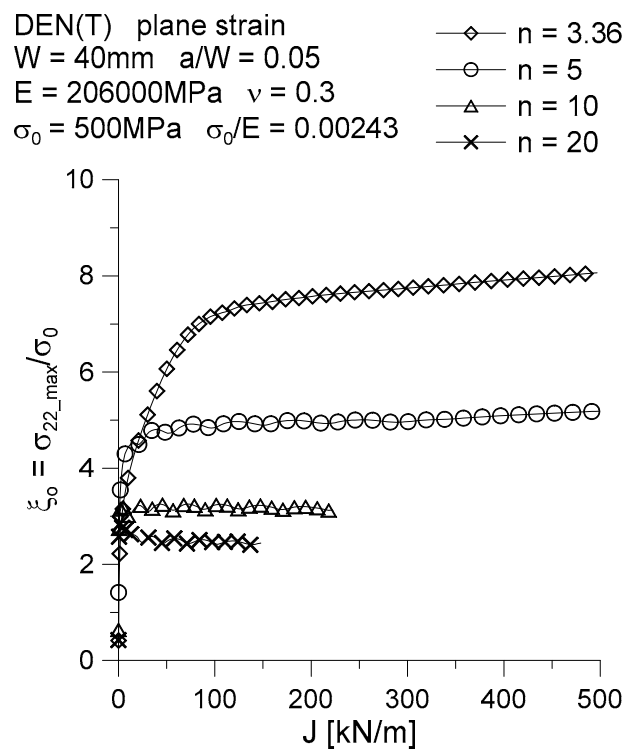

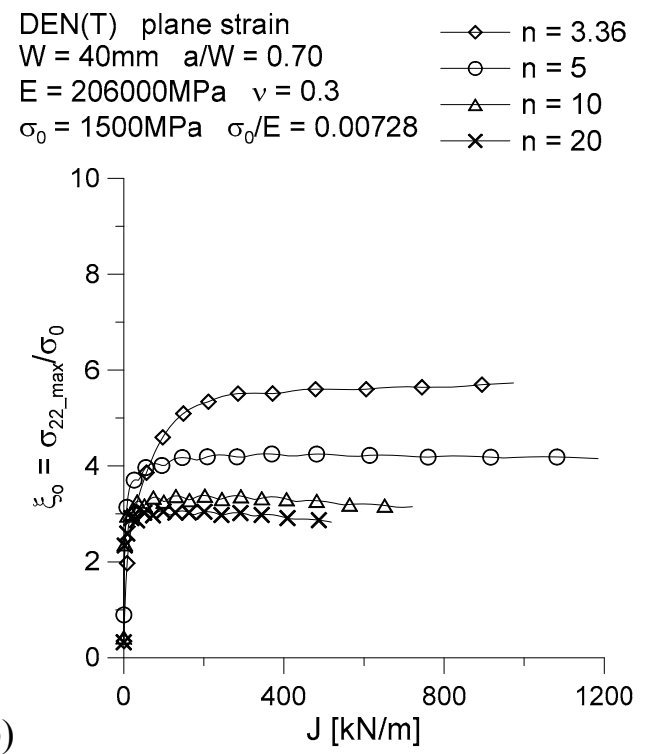

Fig14. The influence of the strain hardening exponent $n$ on the $\xi_{o}=\xi_{o}(J)$ trajectories for DEN(T) plates. 
a)

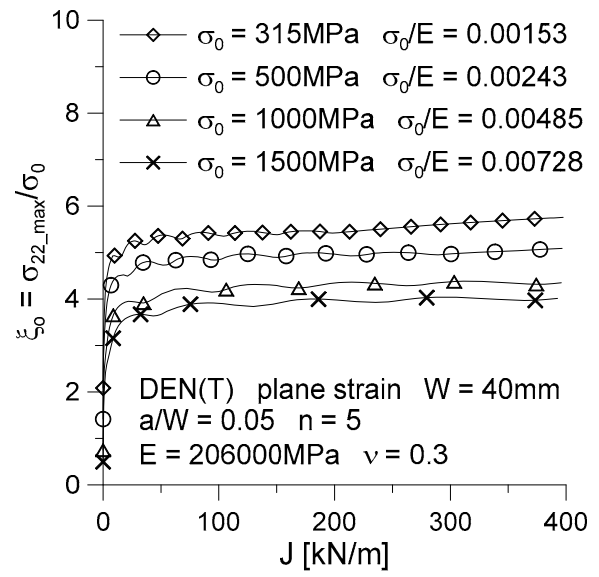

b)

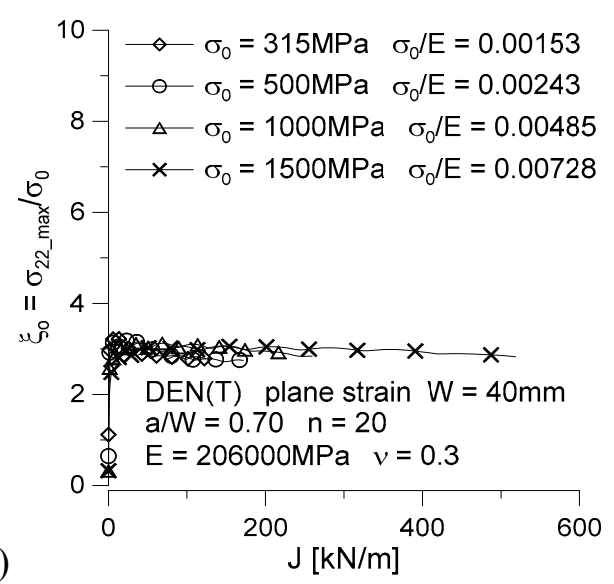

Fig. 15. The influence of the yield stress $\sigma_{0}$ on the $\xi_{o}=\xi_{o}(J)$ trajectories for DEN(T) plates.

The shape of the $\xi_{o}=\xi_{o}(J)$ trajectories does not depend on the relative crack length. Figure 16a shows no effect of the relative crack length on the $\xi_{o}=\xi_{o}(J)$ trajectories for strongly hardening materials $(n=3.36)$. A negligible impact of the crack length is observed for weakly and very weakly hardening materials $(n=10$ and $n=20$ ), as can be seen from Fig.16b [15-17].

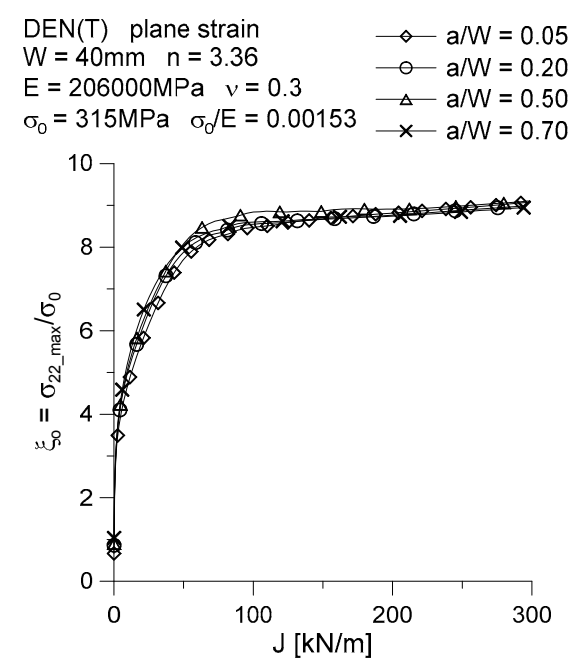

a)

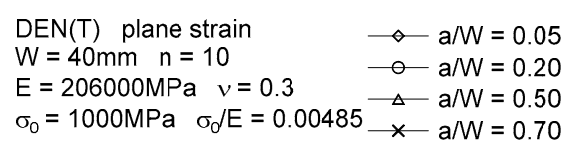

b)

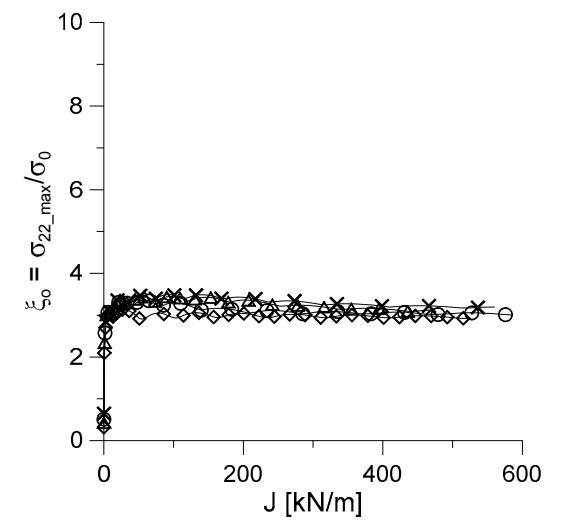

Fig.16. The influence of the relative crack length $a / W$ on the $\xi_{o}=\xi_{o}(J)$ trajectories for DEN(T) plates.

The analysis of the $\xi_{o}=\xi_{o}(J)$ trajectories requires assessing the change in the position of the maximum crack opening stress, denoted as $r_{22} \max$, resulting from an increase in the external load [15-17]. It should be noted that the physical distance between the position of the maximum crack opening stress and the crack tip increases with increasing the external load [15-17]. However, due to the fact that the fracture criteria $[13,14]$ use the normalized distance between the crack tip and the position of the maximum crack opening stress, denoted as $\psi_{o}=\left(r_{22} \max \cdot \sigma_{0}\right) / J$, the analysis will be done for selected graphs showing the relationship $\psi_{o}=\psi_{o}(J)$. An increase in the external load causes a decrease in the normalized position of the maximum crack opening stress, and the $\psi_{o}=\psi_{o}(J)$ trajectories tend to achieve the saturation level (Figs 17 and 18) [15-17]. From Fig.17a it is evident that the more strongly hardening materials, the lower the values of the normalized position of the maximum crack opening stress. The greater the degree of the material hardening, the lower the curves $\psi_{o}=\psi_{o}(J)$ lie (Fig.17a) [15-17]. An increase in the yield strength is accompanied by an increase in the normalized position of the maximum crack opening stress (Fig.17b); the 
higher the yield strength, the higher the curves $\psi_{o}=\psi_{o}(J)$ lie. It should be noted that the normalized position of the maximum crack opening stress is slightly affected by a change in the crack length (Fig.18) [15-17].

a)

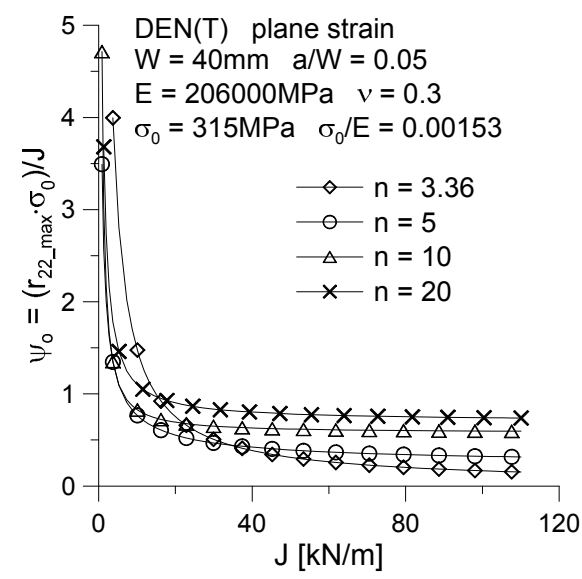

b)

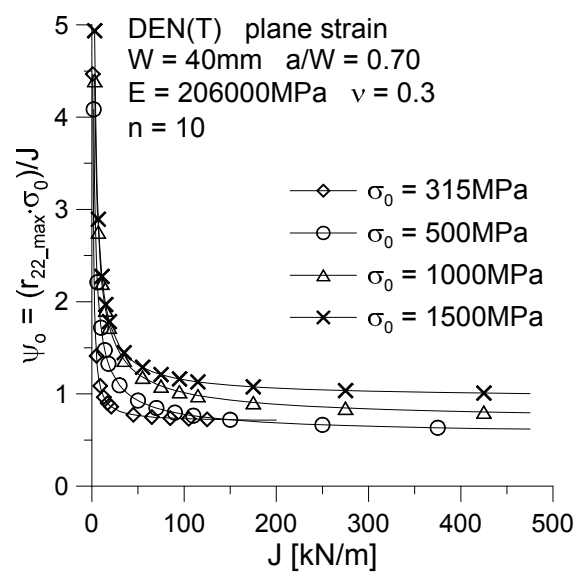

Fig.17. The influence of the strain hardening exponent $n$ (a) and the yield stress $\sigma_{0}$ (b) on the $\psi_{o}=\psi_{o}(J)$ trajectories for $\mathrm{DEN}(\mathrm{T})$ plates.

Table 4. The values of the maximum crack opening stress $\xi_{0}=\sigma_{22} \max / \sigma_{0}$ for the saturation level of the $\xi_{o}=\xi_{o}(J)$ trajectories for $\mathrm{DEN}(\mathrm{T})$ plates in plane strain state.

\begin{tabular}{|c|c|c|c|c|c|c|c|c|c|}
\hline \multicolumn{5}{|c|}{$\sigma_{0}=315 \mathrm{MPa} \quad \sigma_{0} / E=0.00153$} & \multicolumn{5}{|c|}{$\sigma_{0}=500 \mathrm{MPa} \quad \sigma_{0} / E=0.00243$} \\
\hline$n$ & $a / W=0.05$ & $a / W=0.20$ & $a / W=0.50$ & $a / W=0.70$ & $n$ & $a / W=0.05$ & $a / W=0.20$ & $a / W=0.50$ & $a / W=0.70$ \\
\hline 3.36 & 8.38 & 8.49 & 8.87 & 8.71 & 3.36 & 7.19 & 7.55 & 7.57 & 7.59 \\
\hline 5 & 5.44 & 5.54 & 5.62 & 5.61 & 5 & 4.98 & 5.07 & 5.08 & 5.14 \\
\hline 10 & 3.31 & 37 & 3.40 & 3.56 & 10 & 3.17 & 3.20 & 3. & 3.40 \\
\hline 20 & 2.51 & 2.55 & 2.67 & 2.81 & 20 & 2.45 & 2.50 & 2.62 & 2.77 \\
\hline \multicolumn{5}{|c|}{$\sigma_{0}=1000 \mathrm{MPa} \quad \sigma_{0} / E=0.00485$} & \multicolumn{5}{|c|}{$\sigma_{0}=1500 \mathrm{MPa} \quad \sigma_{0} / E=0.00728$} \\
\hline$n$ & $a / W=0.05$ & $a / W=0.20$ & $a / W=0.50$ & $a / W=0.70$ & $n$ & $a / W=0.05$ & $a / W=0.20$ & $a / W=0.50$ & $a / W=0.70$ \\
\hline 3.36 & 6.10 & 6.21 & 6.19 & 6.26 & 3.36 & 5.48 & 5.56 & 5.57 & 5.59 \\
\hline 5 & 4.36 & 4.43 & 4.47 & 4.48 & 5 & 4.04 & 4.10 & 4.14 & 4.14 \\
\hline 10 & 2.96 & 3.04 & 3.07 & 3.24 & 10 & 2.85 & 2.95 & 3.07 & 3.24 \\
\hline 20 & 2.39 & 2.53 & 2.85 & 2.96 & 20 & 2.37 & 2.71 & 2.87 & 2.94 \\
\hline
\end{tabular}

Table 5. The values of the normalized position of the maximum crack opening stress $\psi_{o}=x_{22} \max _{0} \cdot \sigma_{0} / J$ near the crack tip for the saturation level of the $\psi_{o}=\psi_{o}(J)$ trajectories for DEN(T) plates in plane strain.

\begin{tabular}{|c|c|c|c|c|c|c|c|c|c|}
\hline \multicolumn{5}{|c|}{$\sigma_{0}=315 \mathrm{MPa} \quad \sigma_{0} / E=0.00153$} & \multicolumn{5}{|c|}{$\sigma_{0}=500 \mathrm{MPa} \quad \sigma_{0} / E=0.00243$} \\
\hline$n$ & $a / W=0.05$ & $a / W=0.20$ & $a / W=0.50$ & $a / W=0.70$ & $n$ & $a / W=0.05$ & $a / W=0.20$ & $a / W=0.50$ & $a / W=0.70$ \\
\hline 3.36 & 0.199 & 0.195 & 0.167 & 0.172 & 3.36 & 0.252 & 0.191 & 0.206 & 0.209 \\
\hline 5 & 0.263 & 0.357 & 71 & 0.368 & 5 & 0.3 & & & 400 \\
\hline 10 & 0.588 & 21 & & & 10 & & & & 699 \\
\hline 20 & 0.758 & 0.771 & 0.856 & 0.871 & 20 & 0.787 & 0.806 & 0.892 & .951 \\
\hline \multicolumn{5}{|c|}{$\sigma_{0}=1000 \mathrm{MPa} \quad \sigma_{0} / E=0.00485$} & \multicolumn{5}{|c|}{$\sigma_{0}=1500 \mathrm{MPa} \quad \sigma_{0} / E=0.00728$} \\
\hline$n$ & $a / W=0.05$ & $a / W=0.20$ & $a / W=0.50$ & $a / W=0.70$ & $n$ & $a / W=0.05$ & $a / W=0.20$ & $a / W=0.50$ & $a / W=0.70$ \\
\hline 3.36 & 0.244 & 0.209 & 0.268 & 0.247 & 3.36 & 0.261 & 0.248 & 0.283 & 0.286 \\
\hline 5 & 0.427 & 0.459 & 0.465 & 0.445 & 5 & 0.455 & 0.500 & 0.514 & 0.496 \\
\hline 10 & 0.665 & 0.718 & 0.747 & 0.836 & 10 & 0.697 & 0.779 & 0.855 & 0.945 \\
\hline 20 & 0.818 & 0.924 & 1.077 & 1.180 & 20 & 0.841 & 1.086 & 1.177 & 1.230 \\
\hline
\end{tabular}




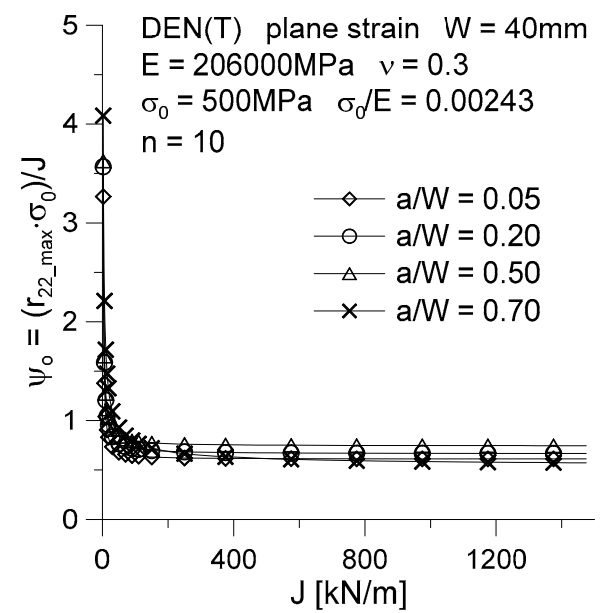

Fig. 18. The influence of the relative crack length $a / W$ on the $\psi_{o}=\psi_{o}(J)$ for DEN(T) plates.

a)

\section{$\mathrm{DEN}(\mathrm{T})$ plane strain $\mathrm{W}=40 \mathrm{~mm}$}

$\mathrm{E}=206000 \mathrm{MPa} \quad v=0.3 \quad \mathrm{n}=3.36$

$\triangleleft \sigma_{0}=315 \mathrm{MPa} \quad\left(\sigma_{d} \mathrm{E}=0.00153\right)$

$\multimap \sigma_{0}=500 \mathrm{MPa} \quad\left(\sigma_{0} / \mathrm{E}=0.00243\right)$

$\triangle \sigma_{0}=1000 \mathrm{MPa} \quad\left(\sigma_{0} / \mathrm{E}=0.00485\right)$

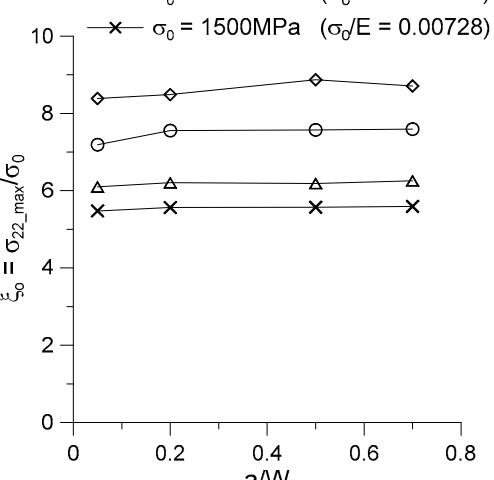

a/W

$\mathrm{DEN}(\mathrm{T})$ plane strain $\mathrm{W}=40 \mathrm{~mm}$

$\mathrm{E}=206000 \mathrm{MPa} \quad v=0.3 \quad \mathrm{n}=5$

$\multimap \sigma_{0}=315 \mathrm{MPa} \quad\left(\sigma_{0} / \mathrm{E}=0.00153\right)$

$\multimap \sigma_{0}=500 \mathrm{MPa} \quad\left(\sigma_{0} / \mathrm{E}=0.00243\right)$

$\triangle \sigma_{0}=1000 \mathrm{MPa} \quad\left(\sigma_{0} / \mathrm{E}=0.00485\right)$

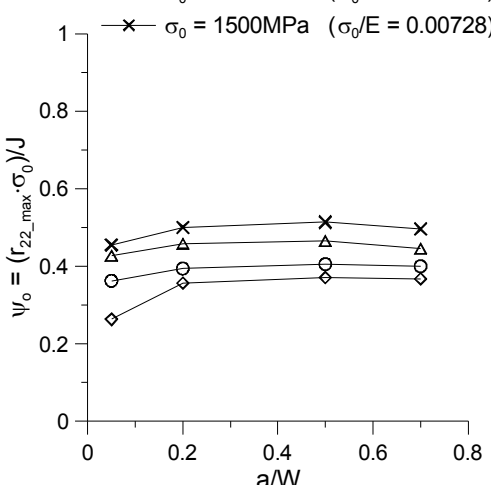

d) a/W

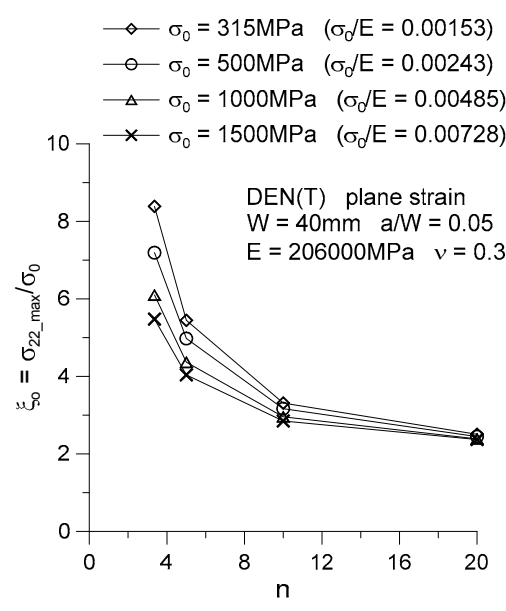

b)

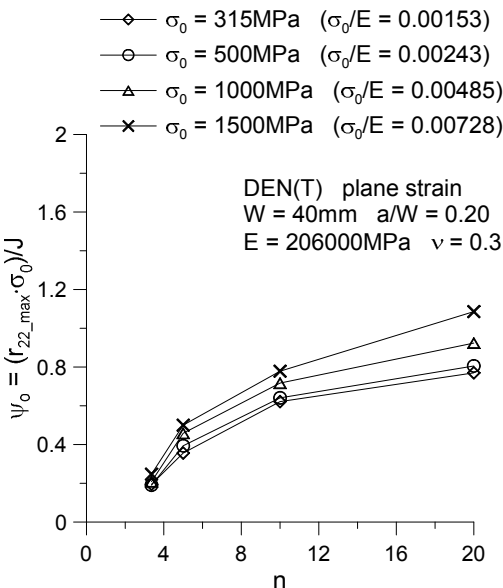

$\operatorname{DEN}(\mathrm{T})$ plane strain

$\mathrm{W}=40 \mathrm{~mm} \quad \mathrm{a} / \mathrm{W}=0.70$

$\mathrm{E}=206000 \mathrm{MPa} \quad v=0.3$

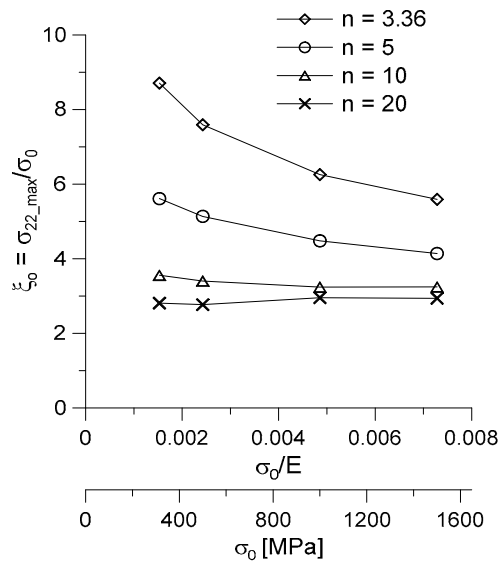

c)

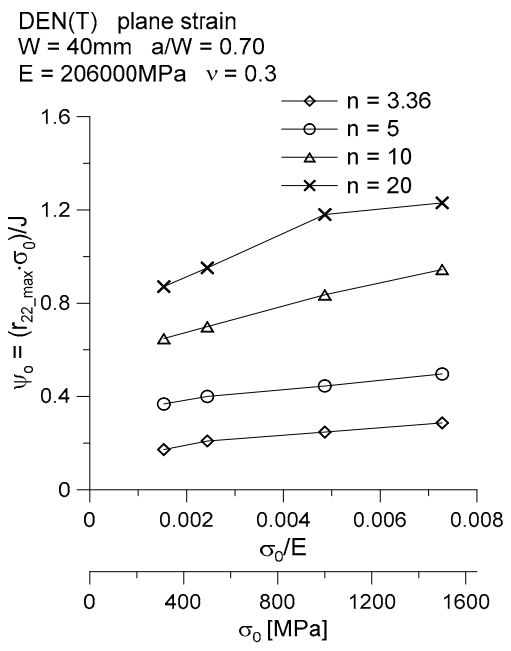

Fig.19. The influence of the relative crack length $a / W$, the strain hardening exponent $n$ and the yield stress $\sigma_{0}$ on the $\xi_{o}$ and $\psi_{o}$ parameters for $\mathrm{DEN}(\mathrm{T})$ plates under plane strain. 
The fact that the trajectories $\xi_{o}=\xi_{o}(J)$ and $\psi_{o}=\psi_{o}(J)$ achieve the saturation level was taken into account in the proposals for the fracture criteria $[13,14]$. Tables 4 and 5 show the values of the maximum crack opening stress $\xi_{o}$ and the value of its normalized position near the crack tip $\psi_{o}$. It is clear that for the saturation level of the trajectories $\xi_{o}=\xi_{o}(J)$ and $\psi_{o}=\psi_{o}(J)$, both parameters $-\xi_{o}$ and $\psi_{o}$ - are slightly dependent on the crack length (see Figures 19a and 19d, respectively) [15-17]. The reduction in the degree of material hardening causes that the values of the parameters $\xi_{o}$ and $\psi_{o}$ for the saturation level decrease and increase, respectively (see Figs $19 \mathrm{~b}$ and 19e, respectively) [15-17]. An increase in the yield strength is accompanied by a decline in the value of the parameter $\xi_{o}$ and a slight increase in the value of the parameter $\psi_{o}$ (see Figs 19c and 19f, respectively) [15-17].

\section{Estimation of the selected fracture parameters - the J-integral, the CTOD, and the load line displacement}

Except for the parameters of geometric constraints - the $Q$-stress, the maximum crack opening stress - there are other parameters such as the $J$-integral, the CTOD, and the load line displacement that require special attention. These parameters were briefly discussed above. Researchers often use them in the analysis of engineering problems. Two of these parameters, i.e., the $J$-integral and the crack tip opening displacement (denoted by $\delta_{T}$ ), can be used to determine the actual fracture toughness (denoted by $K_{C}$ in [9, 10]), as recommended in the SINTAP [9] or FITNET [10] procedures. The $J$-integral is a parameter that controls the stress field in front of the crack tip [1,2]. The load line displacement denoted as $v_{L L}$ may be necessary for the assessment of the limit loads when the $\operatorname{DEN}(\mathrm{T})$ plate is used to represent idealized complex structural elements.

The analysis of elastic-plastic materials involved discussing the influence of the yield stress, $\sigma_{0}$, the strain hardening exponent, $n$, and the relative crack length, $a / W$, on the value of the $J$-integral, CTOD and the load line displacement $v_{L L}$. The analysis was performed for the $J$-integral, the CTOD and the load line displacement as a function of the external load, $P$, normalized by the limit load, $P_{0}$. The analysis results are illustrated in Figs 20-22. As can be seen, the higher the yield stress of the material, the greater the values of the $J$-integral, the CTOD and the load line displacement $v_{L L}$ at the same level of the normalized external load $P / P_{0}$. For higher values of the yield stress, all the parameters - the $J$-integral, the CTOD and $v_{L L}-$ grow faster with a change in the external load (see Figs 20a, 21a and 22a, respectively).

The rate of change (the rate of growth) of the $J=f\left(P / P_{0}\right), \delta_{\mathrm{T}}=f\left(P / P_{0}\right)$ and $v_{L L}=f\left(P / P_{0}\right)$ curves depends on the strain hardening exponent, $n$. The less strongly hardening the material is, the higher the values of the $J$-integral, the CTOD and $v_{L L}$ for a load exceeding the limit load. The $J=f\left(P / P_{0}\right), \delta_{\mathrm{T}}=f\left(P / P_{0}\right)$ and $v_{L L}=f\left(P / P_{0}\right)$ curves plotted for materials characterized by $n=10$ and $n=20$ change more rapidly; there is an increase in the relevant parameters (Figs 20b, 21b and 22b, respectively).

When the influence of the relative crack length, $a / W$, is analyzed, it should be noted that for longer cracks, the values of the $J$-integral and the CTOD are higher at the same level of the normalized external load $P / P_{0}$ (Figs $20 \mathrm{c}$ and $21 \mathrm{c}$, respectively). However, in the case of the load line displacement $v_{L L}$, the opposite situation is observed; the obvious conclusion is that the shorter the crack, the higher the values of the load line displacement $v_{L L}$ at the same level of the normalized external load $P / P_{0}$ (Fig.22c). The similar conclusions shown in [31]. 
a)

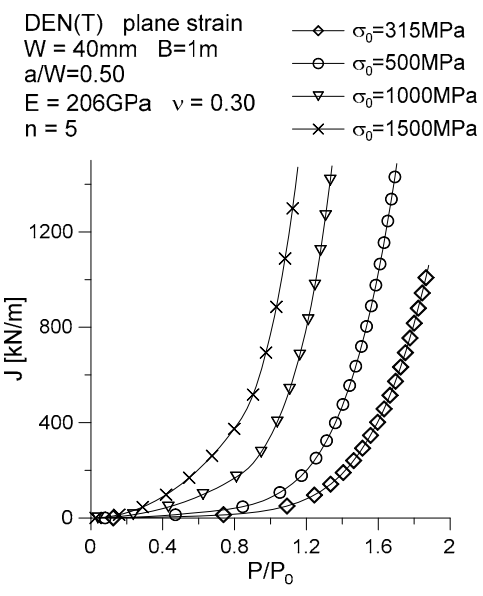

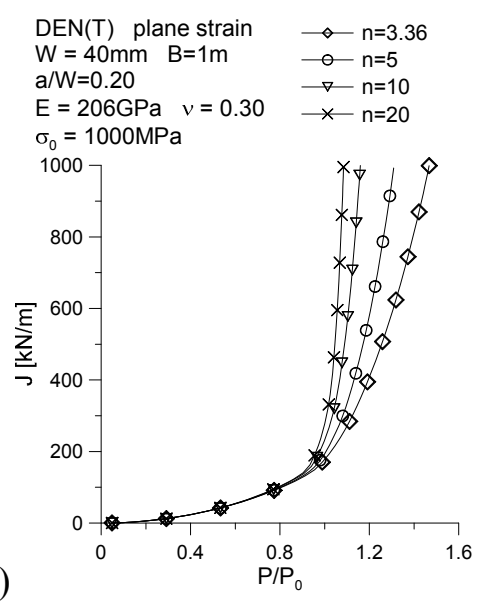

b)

c)

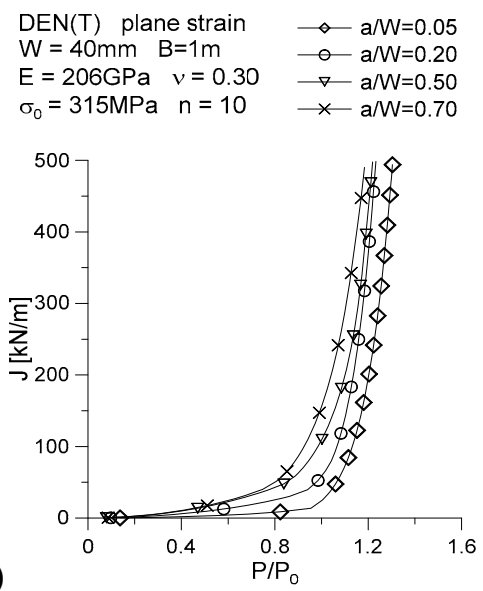

Fig.20. The infuence of the yield stress, the strain hardening exponent and the relative crack length on the $J$ integral for $\mathrm{DEN}(\mathrm{T})$ plates in plane strain.
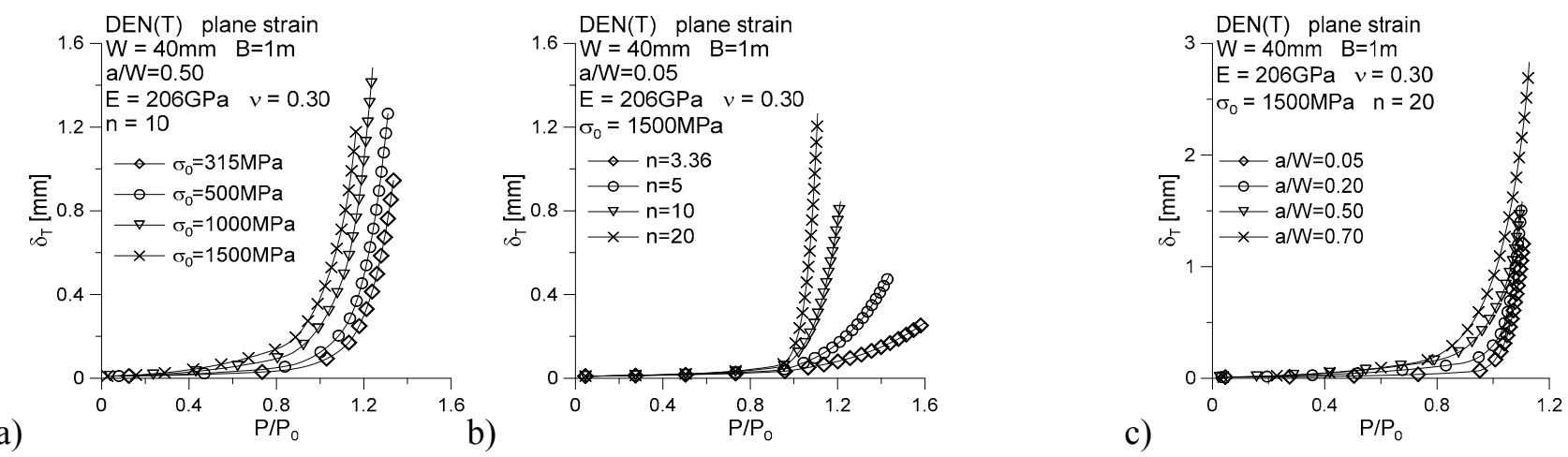

Fig.21. The infuence of the yield stress, the strain hardening exponent and the relative crack length on the CTOD for DEN(T) plates in plane strain.
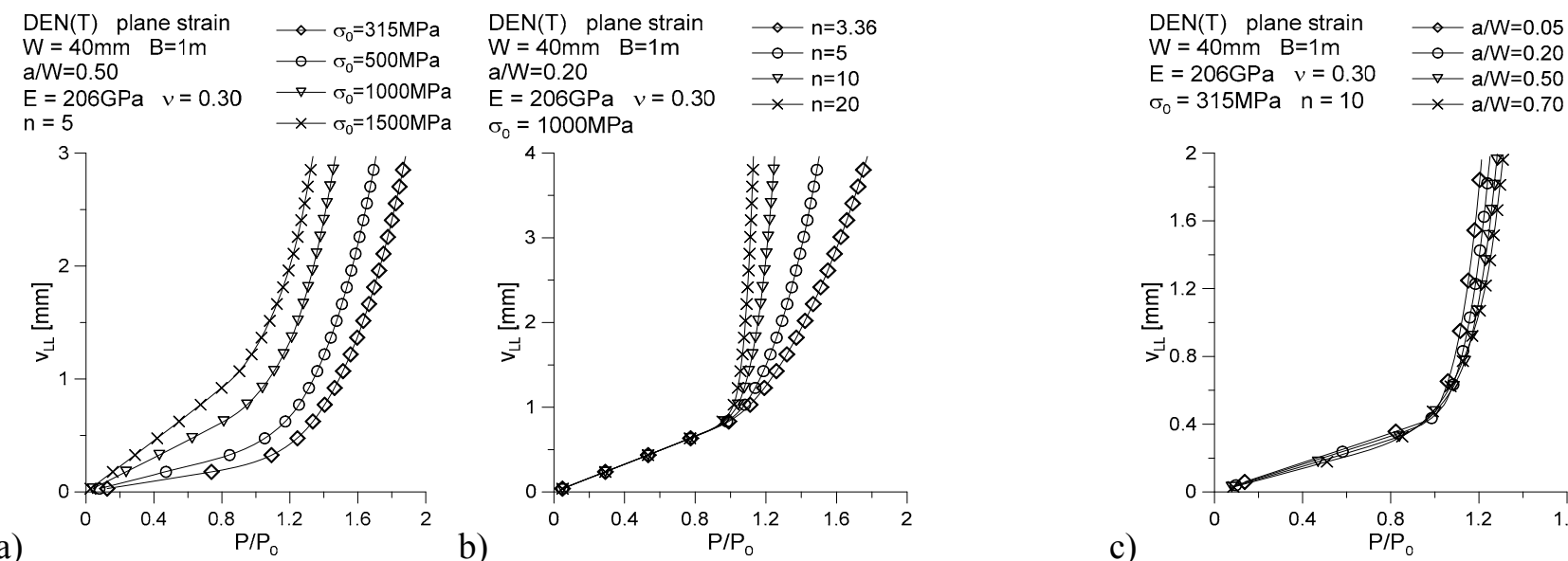

a)

b)

Fig.22. The infuence of the yield stress, the strain hardening exponent and the relative crack length on the load line displacemnt $v_{L L}$ for $\mathrm{DEN}(\mathrm{T})$ plates under plane strain. 


\section{Approximation of the selected numerical results}

All the numerical results presented in this paper can be very useful in solving engineering problems. However, the use of data in the form of tables and graphs can be tedious. That is why the numerical results were approximated using relatively simple mathematical formulae.

\section{Approximation of the limit loads for DEN(T) plates}

From the EPRI procedures [19] it is evident that the limit load is a function of the yield stress, $\sigma_{0}$, and the specimen geometric dimensions: the thickness, $B$, the crack length, $a$ (or $a / W$ ), and the width, $W$

$$
P_{0}=f\left(\sigma_{0}, B, \frac{a}{W}, W\right),
$$

which can be written as

$$
P_{0}=\sigma_{0} \cdot B \cdot f\left(\frac{a}{W}, W\right)
$$

If we assume the specimen thickness $B=1 \mathrm{~mm}$ for plane stress and $B=1 \mathrm{~m}$ for plane strain, in the above expression, only the function $f(a / W, W)$ is unknown. The next step of the approximation procedure involves normalizing all the numerical results of the limit loads by the product of the yield stress and the unit thickness $(B=1 \mathrm{~mm}$ or $B=1 \mathrm{~m})$ and generating a graph showing the relationship between the expression $P_{0} /\left(\sigma_{0} \cdot B\right)$ and the length of the uncracked ligament of the specimen (denoted as $b$ ) - Fig.23.

As shown in Fig.23, the relationship between the expression $P_{0} /\left(\sigma_{0} \cdot B\right)$ and $b$ is slightly non-linear. The function $f(a / W, W)$, which appeared in Eq.(13), can thus be expressed as:

- the linear approximation

$$
\begin{aligned}
& f\left(\frac{a}{W}, W\right)=1995.4 \cdot b+4.5237 \quad \text { for plane stress with } R^{2}=0.9925 \\
& f\left(\frac{a}{W}, W\right)=1619.3 \cdot b+30.253 \quad \text { for plane strain with } R^{2}=0.9934
\end{aligned}
$$

- the polynomial approximation

$$
\begin{aligned}
& f\left(\frac{a}{W}, W\right)=-1213920.44 \cdot b^{3}+65946.22 \cdot b^{2}+1152.25 \cdot b+5.92 \\
& \text { for plane stress with } R^{2}=1 \\
& f\left(\frac{a}{W}, W\right)=498609.99 \cdot b^{3}-56814.35 \cdot b^{2}+3452.84 \cdot b+14.14 \\
& \text { for plane strain with } R^{2}=1
\end{aligned}
$$

- the power function approximation 


$$
\begin{aligned}
& f\left(\frac{a}{W}, W\right)=-40.464015+608.08805 \cdot b^{0.49746} \text { for plane stress with } R^{2}=0.99810224 \\
& f\left(\frac{a}{W}, W\right)=-15.517326+450.13333 \cdot b^{0.44179772} \text { for plane strain with } R^{2}=0.99998906
\end{aligned}
$$

In the above equations, $b$ is the uncracked ligament calculated as $b=(W-a)=(W-a / W \cdot W)$.

a)

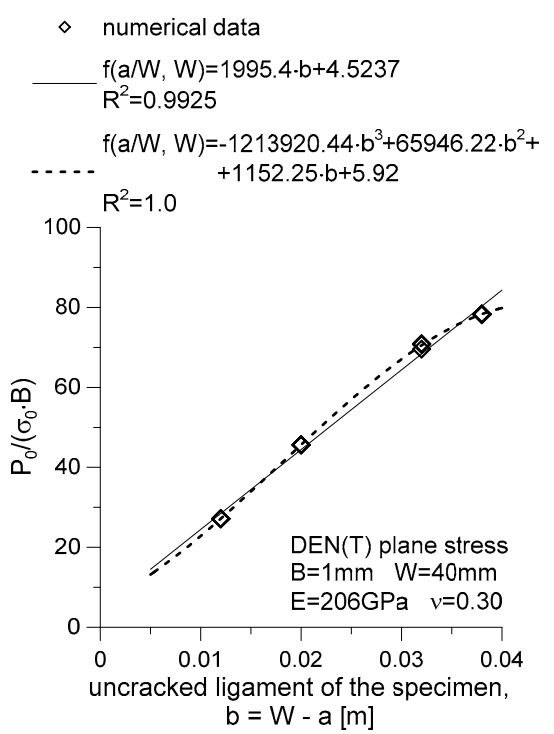

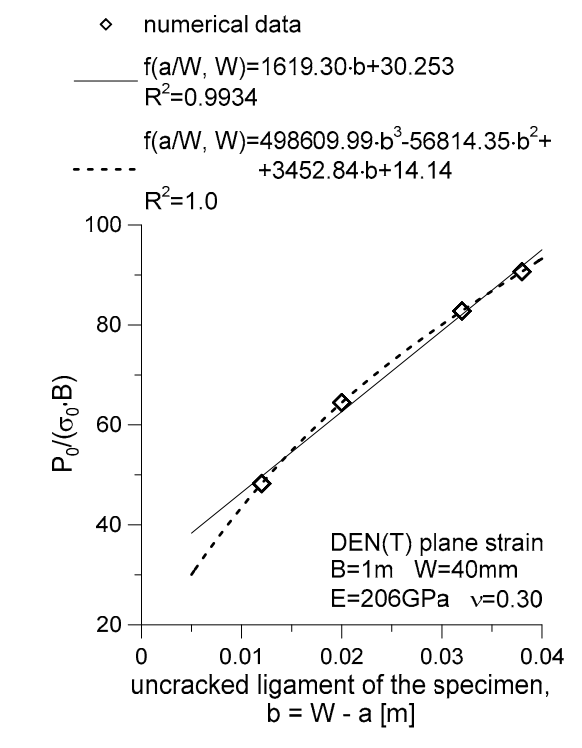

b)

Fig.23. The auxiliary graphs used in the approximation of the numerical results of the limit loads for $\operatorname{DEN}(\mathrm{T})$ plates: a) plane stress; b) plane strain.

Using Eq.(3.2) and any of Eqs (3.3)-(3.8) requires introducing the yield stress, $\sigma_{0}$, in [MPa], the thickness, $B$, in $[\mathrm{m}]$ and the length of the uncracked ligament, $b$, in $[\mathrm{m}]$. The result of the limit load, $P_{0}$, is given in [kN]. The use of Eqs (3.3) and (3.4) led to average errors of 3.92\% and $1.97 \%$ for plane stress and plane strain, respectively. When Eqs (3.5) and (3.6) were used, the errors were $0.2 \%$ and $0.03 \%$ for plane stress and plane strain, respectively. The use of Eqs (3.7) and (3.8) gave a load estimation error of $1.33 \%$ and $0.07 \%$ for plane stress and plane strain, respectively.

The TableCurve 3D program [29] can also be used to propose a different approximation formula to calculate the limit loads, $P_{0}$. Figure 24 shows the limit load, $P_{0}$, versus the yield stress, $\sigma_{0}$, versus the relative crack length, $a / W$. In the TableCurve 3D program [29], the limit loads for plane stress and plane strain were approximated using the function in the following form

$$
P_{0}=A_{1}+A_{2} \cdot \sigma_{0}+A_{3} \cdot\left(\frac{a}{W}\right)+A_{2} \cdot\left(\sigma_{0}\right)^{2}+A_{5} \cdot\left(\frac{a}{W}\right)^{2}+A_{6} \cdot \sigma_{0} \cdot\left(\frac{a}{W}\right)
$$

where the coefficients $A_{1}, A_{2}, A_{3}, A_{4}, A_{5}, A_{6}$ are given in Tab.6.

The use of Eq.(3.9) requires the knowledge of the relative crack length, $a / W$, and the yield stress, $\sigma_{0}$, given in $[\mathrm{MPa}]$. The result will be calculated in $[\mathrm{kN}]$. Formula (3.9) will correctly estimate the limit load for plates with the material and geometric characteristics considered in this paper. It is important to note that the data were obtained for the reference thicknesses $B=1 \mathrm{~mm}$ (plates under plane stress) and $B=1 \mathrm{~m}$ (plates under plane strain). The conversion of a result to another thickness requires the multiplication of the result by the value of the thickness inserted in the appropriate unit - in $[\mathrm{mm}]$ for plane stress and in $[\mathrm{m}]$ for plane strain. 
a)
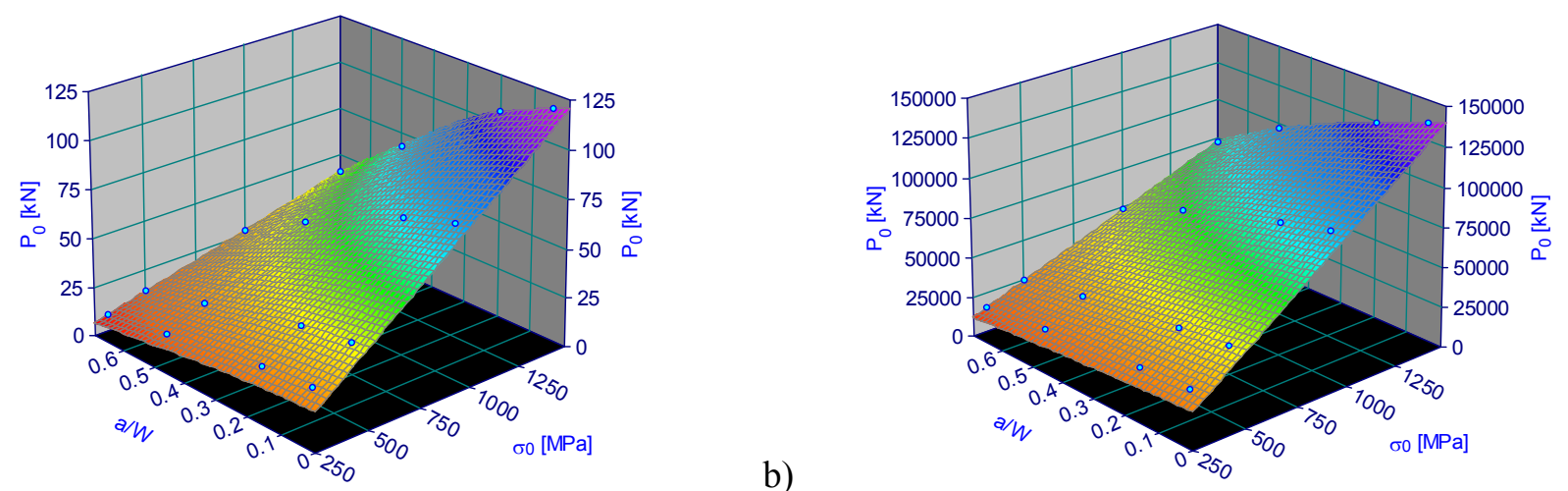

Fig.24. The calculated limit loads as a function of the yield stress and the relative crack length: a) plane stress; b) plane strain.

Table 6. The coefficients of Eq.(3.9) for calculating the limit load for DEN(T) plates under plane stress and plane strain.

\begin{tabular}{|l|c|c|c|c|c|c|c|}
\hline & $A_{1}$ & $A_{2}$ & $A_{3}$ & $A_{4}$ & $A_{5}$ & $A_{6}$ & $R^{2}$ \\
\hline plane stress & -1.9027 & 0.0827 & 23.9696 & $8.432 e-07$ & -32.033 & -0.0797 & 0.999 \\
\hline plane strain & -1975.46 & 95.01 & 19613.52 & $-2.645 e-06$ & -26157.12 & -64.805 & 1.000 \\
\hline
\end{tabular}

\section{Approximation of the $\mathrm{J}-\mathrm{Q}$ trajectories}

The $Q$-stress in $\operatorname{SEN}(\mathrm{B}), \mathrm{CC}(\mathrm{T})$ and $\operatorname{SEN}(\mathrm{T})$ plates can be calculated on the basis of the external load, the material properties, and the plate geometry using various mathematical formulae available in the literature [4-6]. The results of the numerical computations of the $J-Q$ trajectories presented in this paper were approximated using a simple $J-Q$ catalog and the universal formula (21), which allowed us to calculate the $Q$-stress taking into consideration all the parameters affecting the $Q$-stress [4-6]. Before the approximation, all the results were shown as graphs $Q=f\left(\log \left(J /\left(a \cdot \sigma_{0}\right)\right)\right)$ [4-6]. Then, all the graphs were approximated by means of a simple mathematical formula, taking into account the material properties, the external load, and the specimen geometry. All the approximations were made for the results recorded at the distance $r=2.0 \cdot J / \sigma_{0}[4-6,15]$.

Each of the obtained trajectories $Q=f\left(\log \left(J /\left(a \cdot \sigma_{0}\right)\right)\right)$ was approximated with a third order polynomial in the form [4-6]

$$
Q\left(J, a, \sigma_{0}\right)=A_{1}+A_{2} \cdot\left(\log \left(\frac{J}{\left(a \cdot \sigma_{0}\right)}\right)\right)+A_{3} \cdot\left(\log \left(\frac{J}{\left(a \cdot \sigma_{0}\right)}\right)\right)^{2}+A_{4} \cdot\left(\log \frac{J}{\left(a \cdot \sigma_{0}\right)}\right)^{3}
$$

where the coefficients $A_{1}, A_{2}, A_{3}, A_{4}$ are dependent on the strain hardening exponent, $n$, the yield stress, $\sigma_{0}$, and the crack length, $a / W$. The fitting of formula (14) to the numerical results for the worst case was $R^{2}=0.951$. For different values of the strain hardening exponent, $n$, the yield stress, $\sigma_{0}$, and the ratio $a / W$, which were not included in the numerical analysis, the coefficients $A, B, C$ and $D$ can be evaluated using a linear or quadratic approximation $[4-6,15]$.

The results of the numerical approximation (all the coefficients of approximation of the numerical results obtained with Eq.(3.10)) are presented in Tabs 7-10.

Figure 25 compares the numerical results and their approximations (Eq.(3.10)) for the $J-Q$ trajectories for several cases of DEN(T) specimens. 

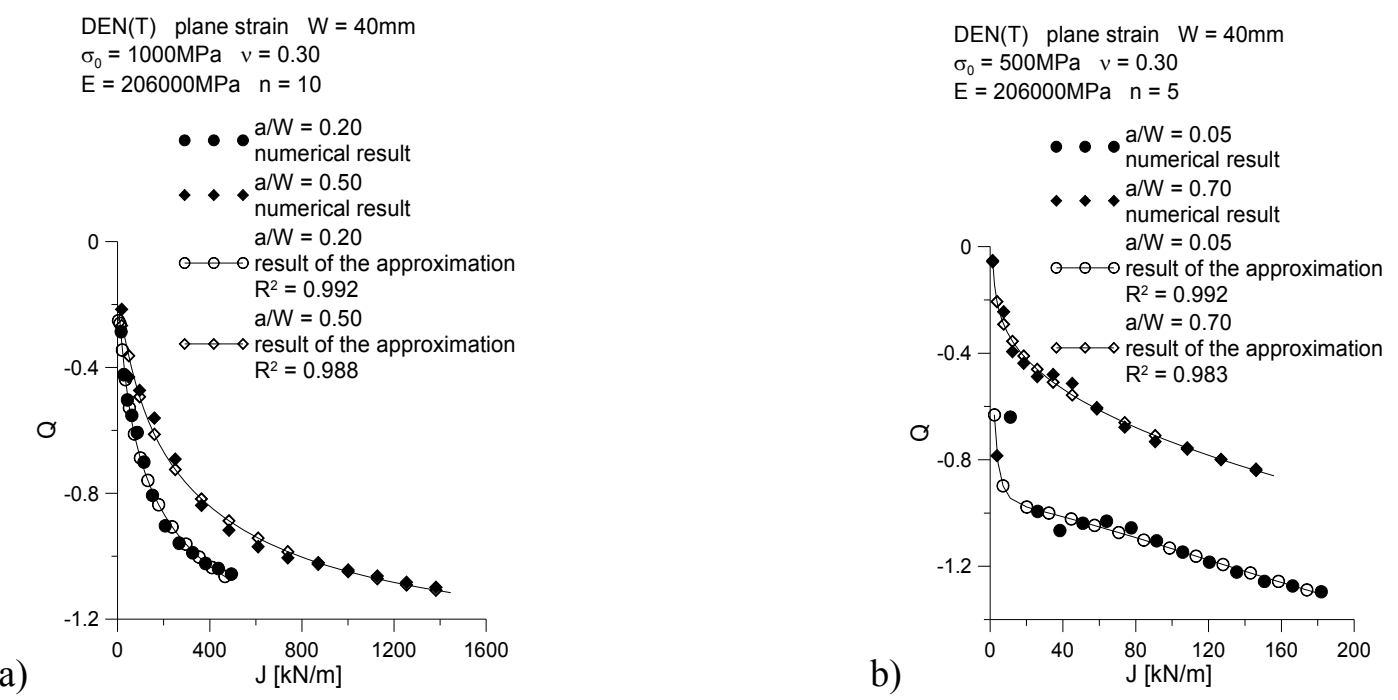

Fig.25. The comparison of the numerical results and their approximations (Eq. (3.10)) for the $J-Q$ trajectories for $\operatorname{DEN}(\mathrm{T})$ specimens: a) $\operatorname{DEN}(\mathrm{T}), \sigma_{0}=1000 \mathrm{MPa}, n=10, a / W=\{0.20,0.50\}$; b) $\mathrm{DEN}(\mathrm{T})$, $\sigma_{0}=500 \mathrm{MPa}, n=5, a / W=\{0.05,0.70\}$ (results for distance $r=2 \cdot J / \sigma_{0}$ ).

Table 7. The coefficients of Eq.(3.10) for DEN(T) specimens with the crack length $a / W=0.05$.

\begin{tabular}{|c|c|c|c|c|c|c|c|c|c|c|c|}
\hline \multicolumn{12}{|c|}{$a / W=0.05$} \\
\hline \multicolumn{3}{|c|}{$\sigma_{0}=315 \mathrm{MPa}$} & \multicolumn{3}{|c|}{$\sigma_{0} / E=0.00153$} & \multicolumn{3}{|c|}{$\overline{\sigma_{0}}=1000 \mathrm{MPa}$} & \multicolumn{3}{|c|}{$\sigma_{0} / E=0.00485$} \\
\hline$n$ & $A_{1}$ & $\overline{A_{2}}$ & $\overline{A_{3}}$ & $\overline{A_{4}}$ & $R^{2}$ & $n$ & $\overline{A_{1}}$ & $\overline{A_{2}}$ & $\overline{A_{3}}$ & $A_{4}$ & $R^{2}$ \\
\hline 3.36 & -2.07367 & -0.89215 & 0.06735 & 0.11350 & 0.988 & 3.36 & -1.61359 & -0.80480 & -0.20500 & -0.02610 & 0.987 \\
\hline 5 & -2.03309 & -0.78086 & 0.21320 & 0.17939 & 0.986 & 5 & -1.84529 & -1.33116 & -0.67673 & -0.15905 & 0.994 \\
\hline 10 & -1.94706 & -1.10762 & -0.42521 & -0.05233 & 0.996 & 10 & -1.78590 & -1.14660 & -0.65380 & -0.18826 & 0.997 \\
\hline 20 & -1.75505 & -0.79796 & -0.38239 & -0.08733 & 0.998 & 20 & -1.66455 & -0.73656 & -0.39118 & -0.14631 & 0.997 \\
\hline \multicolumn{3}{|c|}{$\sigma_{0}=500 \mathrm{MPa}$} & \multicolumn{3}{|c|}{$\sigma_{0} / E=0.00243$} & \multicolumn{3}{|c|}{$\sigma_{0}=1500 \mathrm{MPa}$} & \multicolumn{3}{|c|}{$\sigma_{0} / E=0.00728$} \\
\hline$n$ & $\overline{A_{1}}$ & $\overline{A_{2}}$ & $\overline{A_{3}}$ & $\overline{A_{4}}$ & $\boldsymbol{R}^{2}$ & $n$ & $A_{1}$ & $\overline{A_{2}}$ & $\overline{A_{3}}$ & $\overline{A_{4}}$ & $\boldsymbol{R}^{2}$ \\
\hline 3.36 & -1.88890 & -0.89944 & -0.08240 & 0.04711 & 0.988 & 3.36 & -1.54215 & -0.94765 & -0.41828 & -0.09489 & 0.994 \\
\hline 5 & -1.95881 & -1.06858 & -0.24585 & 0.00375 & 0.989 & 5 & -1.72690 & -1.21018 & -0.61030 & -0.14763 & 0.997 \\
\hline 10 & -1.89073 & -1.19587 & -0.62361 & -0.14589 & 0.997 & 10 & -1.68748 & -0.90117 & -0.38556 & -0.10917 & 0.996 \\
\hline 20 & -1.72213 & -0.81693 & -0.45979 & -0.13738 & 0.999 & 20 & -1.61152 & -0.53061 & -0.09475 & -0.04854 & 0.995 \\
\hline
\end{tabular}

Table 8. The coefficients of Eq.(3.10) for DEN(T) specimens with the crack length $a / W=0.20$.

\begin{tabular}{|c|c|c|c|c|c|c|c|c|c|c|c|}
\hline \multicolumn{10}{|c|}{$a / W=0.20$} \\
\hline \multicolumn{10}{|c|}{$\sigma_{0} / E=0.00153$} & \multicolumn{3}{c|}{$\sigma_{0}=1000 \mathrm{MPa}$} & \multicolumn{3}{c|}{$\sigma_{0} / E=0.00485$} \\
\hline$n$ & $A_{1}$ & $A_{2}$ & $A_{3}$ & $A_{4}$ & $R^{2}$ & $n$ & $A_{1}$ & $A_{2}$ & $A_{3}$ & $A_{4}$ & $R^{2}$ \\
\hline 3.36 & -2.47366 & -2.13286 & -1.11055 & -0.22243 & 0.996 & 3.36 & -1.77026 & -1.19761 & -0.49603 & -0.08822 & 0.992 \\
\hline 5 & -2.54393 & -2.46772 & -1.47359 & -0.32322 & 0.999 & 5 & -1.72418 & -0.94326 & -0.32122 & -0.05836 & 0.991 \\
\hline 10 & -2.12863 & -1.64934 & -1.03481 & -0.25525 & 1.000 & 10 & -1.48214 & -0.17632 & 0.19798 & 0.03791 & 0.992 \\
\hline 20 & -1.90141 & -1.08278 & -0.70365 & -0.20207 & 0.999 & 20 & -1.35798 & 0.33459 & 0.57005 & 0.11015 & 0.994 \\
\hline \multicolumn{8}{|c|}{$\sigma_{0}=500 \mathrm{MPa}$} & \multicolumn{10}{c|}{$\sigma_{0} / E=0.00243$} & \multicolumn{6}{c|}{$\sigma_{0}=1500 \mathrm{MPa}$} & \multicolumn{3}{c|}{$\sigma_{0} / E=0.00728$} \\
\hline$n$ & $A_{1}$ & $A_{2}$ & $A_{3}$ & $A_{4}$ & $R^{2}$ & $n$ & $A_{1}$ & $A_{2}$ & $A_{3}$ & $A_{4}$ & $R^{2}$ \\
\hline 3.36 & -2.31522 & -2.13297 & -1.17072 & -0.24361 & 0.998 & 3.36 & -1.50169 & -0.79934 & -0.25750 & -0.04083 & 0.994 \\
\hline 5 & -2.31777 & -2.16440 & -1.27027 & -0.28244 & 0.998 & 5 & -1.49805 & -0.56724 & -0.06858 & -0.00391 & 0.994 \\
\hline 10 & -1.95283 & -1.31720 & -0.77653 & -0.20126 & 0.997 & 10 & -1.38530 & -0.00799 & 0.35391 & 0.07946 & 0.994 \\
\hline 20 & -1.74884 & -0.72173 & -0.39705 & -0.13488 & 0.997 & 20 & -1.33615 & 0.35823 & 0.64807 & 0.13937 & 0.995 \\
\hline
\end{tabular}


Table 9. The coefficients of Eq.(3.10) for DEN(T) specimens with the crack length $a / W=0.50$.

\begin{tabular}{|c|c|c|c|c|c|c|c|c|c|c|c|}
\hline \multicolumn{12}{|c|}{$a / W=0.50$} \\
\hline \multicolumn{3}{|c|}{$\sigma_{0}=315 \mathrm{MPa}$} & \multicolumn{3}{|c|}{$\sigma_{0} / E=0.00153$} & \multicolumn{3}{|c|}{$\sigma_{0}=1000 \mathrm{MPa}$} & \multicolumn{3}{|c|}{$\sigma_{0} / E=0.00485$} \\
\hline$n$ & $\overline{A_{1}}$ & $A_{2}$ & $A_{3}$ & $A_{4}$ & $R^{2}$ & $n$ & $\overline{A_{1}}$ & $A_{2}$ & $A_{3}$ & $A_{4}$ & $R^{2}$ \\
\hline 3.36 & -2.02121 & -1.20031 & -0.55211 & -0.11394 & 0.994 & 3.36 & -1.61618 & -0.63416 & -0.19976 & -0.04378 & 0.993 \\
\hline 5 & -1.77084 & -0.70633 & -0.31624 & -0.08370 & 0.994 & 5 & -1.32823 & 0.03146 & 0.17593 & 0.01647 & 0.993 \\
\hline 10 & -1.57618 & -0.39747 & -0.20198 & -0.07725 & 0.995 & 10 & -1.02601 & 0.68308 & 0.52993 & 0.07003 & 0.992 \\
\hline 20 & -1.47576 & -0.28518 & -0.18420 & -0.08353 & 0.994 & 20 & -0.84870 & 1.01421 & 0.69381 & 0.09180 & 0.990 \\
\hline \multicolumn{3}{|c|}{$\sigma_{0}=500 \mathrm{MPa}$} & \multicolumn{3}{|c|}{$\sigma_{0} / E=0.00243$} & \multicolumn{3}{|c|}{$\sigma_{0}=1500 \mathrm{MPa}$} & \multicolumn{3}{|c|}{$\sigma_{0} / E=0.00728$} \\
\hline$n$ & $A_{1}$ & $A_{2}$ & $A_{3}$ & $A_{4}$ & $R^{2}$ & $n$ & $A_{1}$ & $A_{2}$ & $A_{3}$ & $A_{4}$ & $R^{2}$ \\
\hline 3.36 & -0.98080 & 0.31452 & 0.38727 & 0.07388 & 0.995 & 3.36 & -0.88938 & 0.36453 & 0.42929 & 0.08772 & 0.995 \\
\hline 5 & -0.79935 & 0.87375 & 0.74924 & 0.13834 & 0.995 & 5 & -0.84132 & 0.71592 & 0.69292 & 0.13818 & 0.994 \\
\hline 10 & -0.53230 & 1.62610 & 1.22887 & 0.22313 & 0.995 & 10 & -0.70112 & 1.28797 & 1.09810 & 0.21449 & 0.992 \\
\hline 20 & -0.26647 & 2.21535 & 1.57465 & 0.28182 & 0.993 & 20 & -0.49749 & 1.81996 & 1.43653 & 0.27571 & 0.991 \\
\hline
\end{tabular}

Table 10. The coefficients of Eq.(3.10) for DEN(T) specimens with the crack length $a / W=0.70$.

\begin{tabular}{|c|c|c|c|c|c|c|c|c|c|c|c|}
\hline \multicolumn{12}{|c|}{$a / W=0.70$} \\
\hline \multicolumn{3}{|c|}{$\sigma_{0}=315 M P a$} & \multicolumn{3}{|c|}{$\sigma_{0} / E=0.00153$} & \multicolumn{3}{|c|}{$\sigma_{0}=1000 M P a$} & \multicolumn{3}{|c|}{$\sigma_{0} / E=0.00485$} \\
\hline$n$ & $A_{1}$ & $A_{2}$ & $A_{3}$ & $A_{4}$ & $R^{2}$ & $n$ & $A_{I}$ & $A_{2}$ & $A_{3}$ & $A_{4}$ & $R^{2}$ \\
\hline 3.36 & -0.75061 & 0.61378 & 0.30881 & 0.01992 & 0.996 & 3.36 & -0.16067 & 1.45602 & 0.91748 & 0.15493 & 0.994 \\
\hline 5 & -0.66643 & 0.67104 & 0.28101 & 0.00473 & 0.994 & 5 & 0.07737 & 2.00341 & 1.23119 & 0.20593 & 0.993 \\
\hline 10 & -1.06174 & -0.29755 & -0.33049 & -0.11106 & 0.988 & 10 & 0.46139 & 2.70876 & 1.60031 & 0.26221 & 0.991 \\
\hline 20 & -1.22360 & -0.75792 & -0.62374 & -0.16668 & 0.982 & 20 & 0.73075 & 3.13806 & 1.80663 & 0.29151 & 0.987 \\
\hline \multicolumn{3}{|c|}{$\sigma_{0}=500 \mathrm{MPa}$} & \multicolumn{3}{|c|}{$\sigma_{0} / E=0.00243$} & \multicolumn{3}{|c|}{$\sigma_{0}=1500 M P a$} & \multicolumn{3}{|c|}{$\sigma_{0} / E=0.00728$} \\
\hline$n$ & $A_{1}$ & $\overline{A_{2}}$ & $A_{3}$ & $A_{4}$ & $R^{2}$ & $n$ & $A_{1}$ & $A_{2}$ & $A_{3}$ & $A_{4}$ & $R^{2}$ \\
\hline 3.36 & -0.59335 & 0.87503 & 0.57452 & 0.08511 & 0.992 & 3.36 & -0.25460 & 1.21163 & 0.80169 & 0.14064 & 0.990 \\
\hline 5 & -0.37133 & 1.19640 & 0.65879 & 0.08433 & 0.988 & 5 & -0.16460 & 1.57475 & 1.04507 & 0.18392 & 0.989 \\
\hline 10 & -0.50978 & 0.77432 & 0.34920 & 0.01759 & 0.975 & 10 & 0.10626 & 2.20998 & 1.42207 & 0.24755 & 0.988 \\
\hline 20 & -0.55892 & 0.53992 & 0.16972 & -0.02127 & 0.966 & 20 & 0.20226 & 2.46975 & 1.58246 & 0.27467 & 0.986 \\
\hline
\end{tabular}

\section{Approximation of the maximum crack opening stress for the saturation level of the $\xi_{o}=\xi_{o}(J)$ curves}

The approximation of the maximum crack opening stress was performed using three-dimensional graphs, which present, in the form of a curved plane, the change in the maximum crack opening stress $\xi_{o}=\sigma_{22} \max _{2} / \sigma_{0}$ (for the saturation level of the $\xi_{0}=\xi_{o}(J)$ trajectories) as a function of the strain hardening exponent, $n$, and the yield strength, $\sigma_{0}$, normalized by Young's modulus, E (Fig.26).

The function selected for the approximation is dependent on two variables - the exponent $n$ in the RO law and the yield strength, $\sigma_{0}$, normalized by Young's modulus, $E$

$$
\begin{aligned}
& \xi_{o}=A_{1}+\frac{A_{2}}{n}+A_{3} \cdot\left(\frac{\sigma_{0}}{E}\right)+\frac{A_{4}}{n^{2}}+A_{5} \cdot\left(\frac{\sigma_{0}}{E}\right)^{2}+\frac{A_{6}}{n} \cdot\left(\frac{\sigma_{0}}{E}\right)+\frac{A_{7}}{n^{3}}+ \\
& +A_{8} \cdot\left(\frac{\sigma_{0}}{E}\right)^{3}+\frac{A_{9}}{n} \cdot\left(\frac{\sigma_{0}}{E}\right)^{2}+\frac{A_{10}}{n^{2}} \cdot\left(\frac{\sigma_{0}}{E}\right)
\end{aligned}
$$

where the approximation coefficients $A_{1} . . A_{10}$ are provided in Tab.11. 
Table 11. The approximation coefficients of formula (3.11) required to calculate the maximum crack opening stress $\xi_{o}$ for DEN(T) plates under plane strain.

\begin{tabular}{|c|c|c|c|c|c|c|c|c|c|c|c|}
\hline$a / W$ & $A_{1}$ & $A_{2}$ & $A_{3}$ & $A_{4}$ & $A_{5}$ & $A_{6}$ & $A_{7}$ & $A_{8}$ & $A_{9}$ & $A_{10}$ & $R^{2}$ \\
\hline 0.05 & 1.985 & 15.56 & -182.26 & 35.88 & 61071.1 & -2630.22 & -23.40 & $-4.80 \cdot 10^{6}$ & 169542.8 & -1127.76 & 0.986 \\
\hline 0.20 & 2.101 & 13.69 & -183.61 & 54.87 & 75028.6 & -3270.73 & -57.53 & $-5.48 \cdot 10^{6}$ & 165453.0 & 6.70 & 0.992 \\
\hline 0.50 & 2.394 & 9.16 & -190.78 & 87.14 & 100976.1 & -4190.57 & -103.71 & $-8.63 \cdot 10^{6}$ & 272417.7 & -574.82 & 0.984 \\
\hline 0.70 & 2.316 & 14.60 & -160.04 & 39.92 & 86055.8 & -3730.67 & -13.72 & $-7.27 \cdot 10^{6}$ & 227198.2 & -506.77 & 0.987 \\
\hline
\end{tabular}

When Eq.(3.11) is employed, the user needs to know the exponent $n$ in the RO law, the yield stress, $\sigma_{0}$, Young's modulus, $E$, and the relative crack length, $a / W$. It should be noted that these values were obtained for the reference thickness $B=1 \mathrm{~m}$.

a)
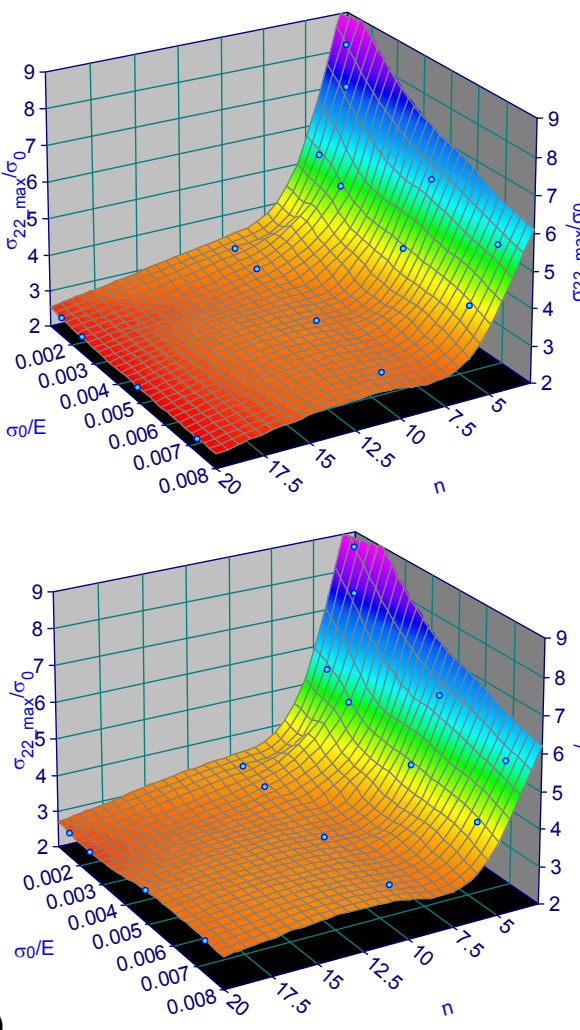

b)

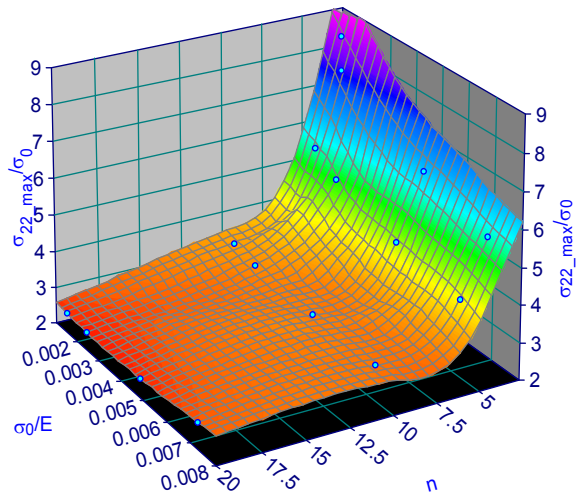

d)

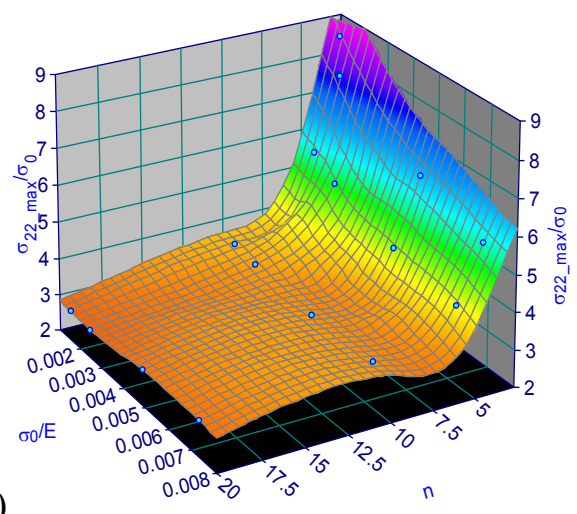

Fig.26. The relationship $\xi_{o}=\xi_{o}\left(n, \sigma_{0} / E\right)$ for DEN(T) plates - influence of the strain hardening exponent $n$ and the yield stress $\sigma_{0}$ normalized by Young's modulus $E$ on the maximum crack opening stress $\xi_{0}=\sigma_{22 \text { max }} / \sigma_{0}$ for various values of the relative crack length $a / W$, for the saturation level of the $\xi_{o}=\xi_{o}(J)$ trajectories: a) $a / W=0.05$; b) $a / W=0.20$; c) $a / W=0.50$; d) $a / W=0.70$.

New elastic-plastic formulae for determining the $J$-integral, the CTOD, and the load line displacement $v_{L L}$

The incompatibility of the numerical results with the results obtained using the algorithm proposed by the authors of the EPRI procedures [19] indicates that it is vital to propose a new hybrid solution to estimate the values of the $J$-integral, the CTOD, and the load line displacement without the need for numerical calculations. The new formulae, based on the discussion presented in [19], can be used to determine the $J$-integral, the CTOD, and the load line displacement; it is possible to omit the decomposition of the elastic and plastic parts of the parameters [31]. The formulae can be written as follows 


$$
\begin{aligned}
& J=\alpha \cdot \sigma_{0} \cdot \varepsilon_{0} \cdot b \cdot\left(\frac{P}{P_{0}}\right)^{n+1} \cdot\left[h_{1}^{*}\left(\frac{a}{W}, n\right)\right]^{n+1}, \\
& \delta=\alpha \cdot \varepsilon_{0} \cdot b \cdot\left(\frac{P}{P_{0}}\right)^{n} \cdot\left[h_{2}^{*}\left(\frac{a}{W}, n\right)\right]^{n}, \\
& \mathrm{v}_{L L}=\alpha \cdot \varepsilon_{0} \cdot b \cdot\left(\frac{P}{P_{0}}\right)^{n} \cdot\left[h_{3}^{*}\left(\frac{a}{W}, n\right)\right]^{n}
\end{aligned}
$$

where $P_{0}$ is the limit load determined numerically (presented in Tab.2 and Eqs (3.2)-(3.8)) while the functions $h_{1}{ }^{*}, h_{2}{ }^{*}$ and $h_{3}{ }^{*}$ are dependent on the strain hardening exponent, $n$, and the relative crack length, $a / W[31]$.

The analysis of the results reveals that the values of the functions $h_{1}{ }^{*}, h_{2}{ }^{*}$ and $h_{3}{ }^{*}$ are strongly dependent on the degree of material hardening expressed by the value of the strain hardening exponent, $n$, the relative crack length, $a / W$, and the external load, $P / P_{0}$. It can be noted that for the case when the external load is equal to or greater than the limit load, $P_{0}$, the $h_{1}{ }^{*}=f\left(P / P_{0}\right), h_{2}{ }^{*}=f\left(P / P_{0}\right)$ and $h_{3}{ }^{*}=f\left(P / P_{0}\right)$ trajectories achieve the saturation level - compare the conclusions in [31]. The hybrid method provided in the EPRI [2] procedures to estimate the $J$-integral, the CTOD, and the load line displacement is based on the fixed values of the functions $h_{1}, h_{2}$ and $h_{3}$ [2], which do not depend on the external load. In his earlier studies [20], the author indicates that the values of the functions $h_{1}, h_{2}$, and $h_{3}$ change with a variation of the external load. The similar conclusions shown in [31].

a)

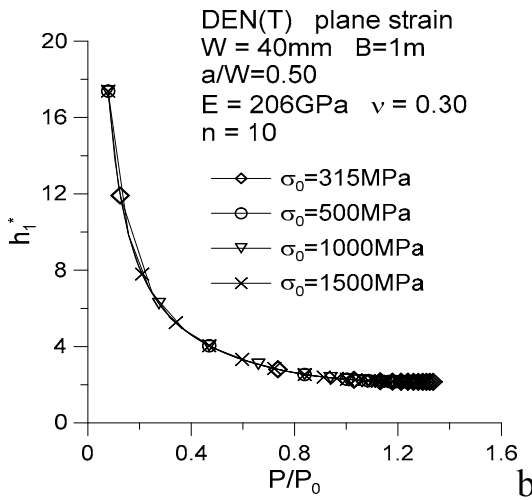

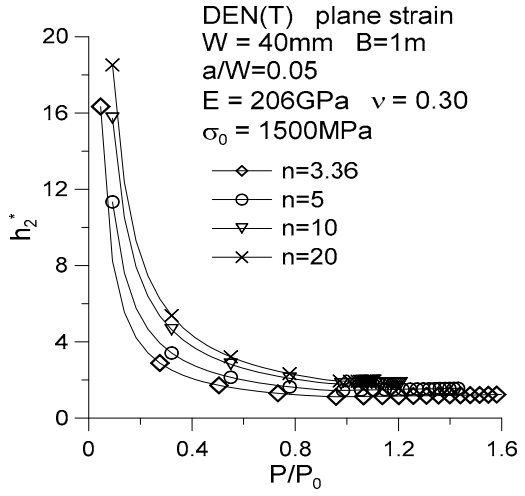

c)

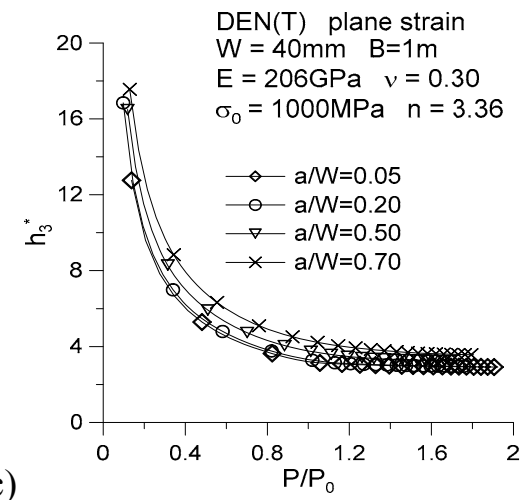

Fig.27. The infuence of the yield stress, the strain hardening exponent and the relative crack length on the functions $h_{1}{ }^{*}, h_{2}{ }^{*}$ and $h_{3}{ }^{*}$ for DEN(T) plates under plane strain conditions (different configurations of the material properties and the relative crack length).

It is quite interesting to note that the functions $h_{1}{ }^{*}, h_{2}{ }^{*}$ and $h_{3}{ }^{*}$ are not dependent on the yield strength (Fig.27a). The values of the functions $h_{1}{ }^{*}, h_{2}{ }^{*}$ and $h_{3}{ }^{*}$ decrease with increasing external load, $P / P_{0}$, and they achieve the saturation level for external loads, $P / P_{0} \geq 1.0$ (Fig.27). The values of the three functions increase with increasing crack length (e.g., Fig.27c). There is a lack of correlation between the functions $h_{1}{ }^{*}, h_{2}{ }^{*}$ and $h_{3}{ }^{*}$ and the yield stress, $\sigma_{0}$, which slightly simplifies the mathematical description of the $h_{1}{ }^{*}=f\left(P / P_{0}\right)$, $h_{2}{ }^{*}=f\left(P / P_{0}\right)$ and $h_{3}{ }^{*}=f\left(P / P_{0}\right)$ curves. The similar observation were observed in the analysis of three-point bending specimens [31]. The functions $h_{1}{ }^{*}=f\left(P / P_{0}\right), h_{2}{ }^{*}=f\left(P / P_{0}\right)$ and $h_{3}{ }^{*}=f\left(P / P_{0}\right)$ can be described using the following mathematical formulae

$$
h_{1}^{*}\left(\frac{a}{W}, n\right)=\frac{a_{1}+c_{1} \cdot\left(\frac{P}{P_{0}}\right)+e_{1} \cdot\left(\frac{P}{P_{0}}\right)^{2}+g_{1} \cdot\left(\frac{P}{P_{0}}\right)^{3}+i_{1} \cdot\left(\frac{P}{P_{0}}\right)^{4}+k_{1} \cdot\left(\frac{P}{P_{0}}\right)^{5}}{1+b_{1} \cdot\left(\frac{P}{P_{0}}\right)+d_{1} \cdot\left(\frac{P}{P_{0}}\right)^{2}+f_{1} \cdot\left(\frac{P}{P_{0}}\right)^{3}+h_{1} \cdot\left(\frac{P}{P_{0}}\right)^{4}+j_{1} \cdot\left(\frac{P}{P_{0}}\right)^{5}},
$$




$$
\begin{aligned}
& h_{2}^{*}\left(\frac{a}{W}, n\right)=\frac{a_{2}+c_{2} \cdot\left(\frac{P}{P_{0}}\right)+e_{2} \cdot\left(\frac{P}{P_{0}}\right)^{2}+g_{2} \cdot\left(\frac{P}{P_{0}}\right)^{3}+i_{2} \cdot\left(\frac{P}{P_{0}}\right)^{4}}{1+b_{2} \cdot\left(\frac{P}{P_{0}}\right)+d_{2} \cdot\left(\frac{P}{P_{0}}\right)^{2}+f_{2} \cdot\left(\frac{P}{P_{0}}\right)^{3}+h_{2} \cdot\left(\frac{P}{P_{0}}\right)^{4}+j_{2} \cdot\left(\frac{P}{P_{0}}\right)^{5}}, \\
& h_{3}^{*}\left(\frac{a}{W}, n\right)=\frac{a_{3}+c_{3} \cdot\left(\frac{P}{P_{0}}\right)+e_{3} \cdot\left(\frac{P}{P_{0}}\right)^{2}+g_{3} \cdot\left(\frac{P}{P_{0}}\right)^{3}+i_{3} \cdot\left(\frac{P}{P_{0}}\right)^{4}+k_{3} \cdot\left(\frac{P}{P_{0}}\right)^{5}}{1+b_{3} \cdot\left(\frac{P}{P_{0}}\right)+d_{3} \cdot\left(\frac{P}{P_{0}}\right)^{2}+f_{3} \cdot\left(\frac{P}{P_{0}}\right)^{3}+h_{3} \cdot\left(\frac{P}{P_{0}}\right)^{4}+j_{3} \cdot\left(\frac{P}{P_{0}}\right)^{5}}
\end{aligned}
$$

where the coefficients of approximation $a_{1} . . k_{1}, a_{2 . . j_{2}}$ and $a_{3 . .} k_{3}$ depend on the value of the strain hardening exponent, $n$, and the relative crack length, $a / W$. The values of the approximation coefficient are presented in Tabs 12-14. In the future, the author intends to create an application to be used for estimating the values of the functions $h_{1}{ }^{*}, h_{2}{ }^{*}$ and $h_{3}{ }^{*}$, and thus the values of the $J$-integral, the CTOD, and the load line displacement for a specific material and a specific geometry, including all basic specimens - for example SEN(B), $\operatorname{DEN}(\mathrm{T}), \operatorname{SEN}(\mathrm{T}), \mathrm{C}(\mathrm{T}), \mathrm{CC}(\mathrm{T})[31]$.

Table 12. The approximation coefficients $a_{1} . k_{l}$ required to estimate the values of the function $h_{l}{ }^{*}$ according

\begin{tabular}{|c|c|c|c|c|c|c|c|c|}
\hline & \multicolumn{4}{|c|}{$a / W=0.05$} & \multicolumn{4}{|c|}{$a / W=0.20$} \\
\hline$n$ & 3.36 & 5 & 10 & 20 & 3.36 & 5 & 10 & 20 \\
\hline$a_{1}$ & 18.69 & 44.42 & 169.62 & 494.03 & 35.61 & 85.09 & 294.42 & 824.08 \\
\hline$b_{1}$ & 36.60 & 63.69 & 160.03 & 350.05 & 77.95 & 132.54 & 279.40 & 581.43 \\
\hline$c_{1}$ & -2.89 & -22.07 & 57.09 & 520.52 & 276.46 & 680.72 & 2021.33 & 5383.31 \\
\hline$d_{1}$ & -145.61 & -218.48 & -264.60 & -54.81 & -30.60 & 152.28 & 785.83 & 2452.82 \\
\hline$e_{1}$ & -146.42 & -233.60 & -914.31 & -3541.59 & -546.21 & -1349.84 & -5045.55 & -16304.14 \\
\hline$f_{1}$ & 265.48 & 380.21 & 162.48 & -1298.64 & 90.18 & -441.72 & -2596.45 & -8698.35 \\
\hline$g_{1}$ & 363.77 & 598.83 & 1388.91 & 3935.83 & 722.99 & 1076.22 & 3564.94 & 13377.63 \\
\hline$h_{1}$ & -252.42 & -379.41 & -182.47 & 1395.96 & -363.00 & 15.04 & 2004.22 & 8078.31 \\
\hline$i_{1}$ & -381.44 & -656.81 & -1122.93 & -1717.68 & -994.92 & -968.13 & -898.01 & -2700.36 \\
\hline$j_{1}$ & 96.45 & 157.64 & 136.94 & -378.71 & 265.93 & 207.73 & -406.37 & -2381.31 \\
\hline$k_{1}$ & 150.63 & 277.18 & 446.80 & 338.07 & 591.75 & 614.94 & 203.01 & -510.89 \\
\hline \multirow[t]{2}{*}{$R^{2}$} & 1.000 & 1.000 & 1.000 & 1.000 & 1.000 & 1.000 & 1.000 & 1.000 \\
\hline & \multicolumn{4}{|c|}{$a / W=0.50$} & \multicolumn{4}{|c|}{$a / W=0.70$} \\
\hline$n$ & 3.36 & 5 & 10 & 20 & 3.36 & 5 & 10 & 20 \\
\hline$a_{1}$ & 44.11 & 136.28 & 525.44 & 1640.89 & 46.28 & 94.75 & 287.28 & 574.53 \\
\hline$b_{1}$ & 78.46 & 217.97 & 522.86 & 1206.90 & 64.30 & 103.57 & 226.54 & 353.57 \\
\hline$c_{1}$ & 398.56 & 2448.15 & 11481.86 & 47968.57 & 250.63 & 447.15 & 1224.82 & 487.65 \\
\hline$d_{1}$ & 32.50 & 1239.50 & 6922.05 & 28186.11 & -92.01 & -62.22 & 226.42 & -114.54 \\
\hline$e_{1}$ & -601.49 & -2156.75 & 13598.02 & 144757.69 & -756.67 & -1542.09 & -4909.58 & -4301.82 \\
\hline$f_{1}$ & -0.96 & -2105.89 & 3571.72 & 65108.58 & 141.65 & -171.16 & -1850.87 & -1440.48 \\
\hline$g_{1}$ & 701.29 & -158.36 & -23563.55 & -222872.86 & 1073.42 & 1689.23 & 4863.76 & 5038.72 \\
\hline$h_{1}$ & -321.20 & 1007.26 & -13392.01 & -123085.37 & -378.66 & -37.14 & 1961.81 & 1813.99 \\
\hline$i_{1}$ & -1090.87 & 361.32 & 1936.20 & 47575.04 & -1392.82 & \begin{tabular}{|l|}
-1350.17 \\
\end{tabular} & -1618.63 & -1960.48 \\
\hline$j_{1}$ & 343.54 & 399.13 & 7974.25 & 48963.77 & 344.83 & 259.46 & -487.72 & -603.24 \\
\hline$k_{1}$ & 894.99 & 1240.17 & 8818.92 & 25102.87 & 1025.37 & 921.99 & 343.82 & 184.91 \\
\hline$R^{2}$ & 1.000 & 1.000 & 1.000 & 1.000 & 1.000 & 1.000 & 1.000 & 1.000 \\
\hline
\end{tabular}
to formula (3.15). 
Table 13. The approximation coefficients $a_{2} \cdot j_{2}$ required to estimate the values of the function $h_{2}{ }^{*}$ according to formula (3.16).

\begin{tabular}{|c|c|c|c|c|c|c|c|c|}
\hline & \multicolumn{4}{|c|}{$a / W=0.05$} & \multicolumn{4}{|c|}{$a / W=0.20$} \\
\hline$n$ & 3.36 & 5 & 10 & 20 & 3.36 & 5 & 10 & 20 \\
\hline$a_{2}$ & 88.46 & 172.90 & -644.91 & -141.04 & 88.46 & 172.90 & -644.91 & -141.04 \\
\hline$b_{2}$ & 94.00 & 142.60 & -481.20 & -127.45 & 94.00 & 142.60 & -481.20 & -127.45 \\
\hline$c_{2}$ & -149.14 & -308.09 & 15053.99 & 1989.92 & -149.14 & -308.09 & 15053.99 & 1989.92 \\
\hline$d_{2}$ & -164.27 & -246.24 & 10878.69 & 1834.36 & -164.27 & -246.24 & 10878.69 & 1834.36 \\
\hline$e_{2}$ & 104.56 & 223.58 & -19985.23 & 25261.78 & 104.56 & 223.58 & -19985.23 & 25261.78 \\
\hline$f_{2}$ & 113.71 & 118.90 & -17982.61 & 10850.07 & 113.71 & 118.90 & -17982.61 & 10850.07 \\
\hline$g_{2}$ & -31.36 & -124.95 & 3547.63 & -29859.75 & -31.36 & -124.95 & 3547.63 & -29859.75 \\
\hline$h_{2}$ & -34.28 & 0.10 & 60 & -10383.67 & -34.28 & 0.10 & 9951.60 & -10383.67 \\
\hline$i_{2}$ & 4.09 & 62.35 & 4966.48 & 12417.56 & 4.09 & 62.35 & 4966.48 & 12417.56 \\
\hline$j_{2}$ & 3.94 & 0.99 & -757.35 & 2725.92 & 3.94 & 0.99 & -757.35 & 2725.92 \\
\hline \multirow[t]{2}{*}{$R^{2}$} & 0.985 & 0.994 & 0.999 & 1.000 & 0.985 & 0.994 & 0.999 & 1.000 \\
\hline & \multicolumn{4}{|c|}{$a / W=0.50$} & \multicolumn{4}{|c|}{$a / W=0.70$} \\
\hline$n$ & 3.36 & 5 & 10 & 20 & 3.36 & 5 & 10 & 20 \\
\hline$a_{2}$ & 135.69 & -1171000.00 & -26285.30 & -128077.61 & 135.68 & -3494.15 & -9859.01 & -1243.58 \\
\hline$b_{2}$ & 105.59 & -938675.39 & -16928.13 & -72648.00 & 95.48 & -2593.17 & -6127.26 & -744.69 \\
\hline$c_{2}$ & 264.34 & 51915900.00 & 1023140.00 & 5014220.00 & -185.62 & 94456.07 & 249521.61 & 21382.34 \\
\hline$d_{2}$ & 304.26 & 42584300.00 & 664400.14 & 2858660.00 & -133.07 & 71337.27 & 160488.43 & 13121.65 \\
\hline$e_{2}$ & -211.47 & -52576000.00 & -822788.76 & -4139400.00 & 174.33 & -79030.38 & 369817.28 & 290717.10 \\
\hline$f_{2}$ & -627.08 & -69553000.00 & -803757.10 & -2974400.00 & 69.31 & -112189.45 & 63208.75 & 148152.40 \\
\hline$g_{2}$ & -209.36 & -1537300.00 & -186755.86 & -2286500.00 & -114.73 & -20567.82 & -499742.16 & -9558.52 \\
\hline$h_{2}$ & 339.87 & 43124900.00 & 282355.52 & -381765.39 & -19.72 & 81663.59 & -123534.81 & -10028.52 \\
\hline$i_{2}$ & 176.34 & 23592500.00 & 332457.94 & 2053440.00 & 28.98 & 81206.75 & 272203.37 & -78120.04 \\
\hline$j_{2}$ & -43.19 & -5806200.00 & 19675.06 & 810657.45 & 3.26 & -8808.10 & 59626.21 & -50807.19 \\
\hline$R^{2}$ & 0.991 & 0.995 & 0.999 & 1.000 & 0.984 & 0.995 & 0.998 & 1.000 \\
\hline
\end{tabular}


Table 14. The approximation coefficients $a_{3} . . k_{3}$ required to estimate the values of the function $h_{3}{ }^{*}$ according to formula (3.17).

\begin{tabular}{|c|c|c|c|c|c|c|c|c|}
\hline & \multicolumn{4}{|c|}{$a / W=0.05$} & \multicolumn{4}{|c|}{$a / W=0.20$} \\
\hline$n$ & 3.36 & 5 & 10 & 20 & 3.36 & 5 & 10 & 20 \\
\hline$a_{3}$ & 126.09 & 231.00 & 516.63 & 1467.40 & 187.99 & 360.94 & 820.52 & 2059.85 \\
\hline$b_{3}$ & 90.48 & 149.38 & 290.56 & 797.20 & 160.84 & 262.73 & 488.24 & 1134.46 \\
\hline$c_{3}$ & 204.66 & 237.59 & -319.27 & 4199.71 & 1658.49 & 2824.50 & 3686.31 & 11811.81 \\
\hline$d_{3}$ & -152.10 & -189.56 & -468.41 & 1618.49 & 358.76 & 831.89 & 1232.03 & 5129.42 \\
\hline$e_{3}$ & -813.86 & -1259.11 & -1254.28 & -16785.02 & -2532.55 & -5379.37 & -10373.43 & -38007.53 \\
\hline$f_{3}$ & 261.56 & 180.44 & 223.21 & -7508.03 & -693.10 & -1977.03 & -4129.93 & -17927.78 \\
\hline$g_{3}$ & 1249.07 & 1710.01 & 2090.35 & 15811.71 & 1403.21 & 3166.39 & 8155.42 & 33310.86 \\
\hline$h_{3}$ & -416.64 & -345.51 & -138.41 & 7274.03 & 72.34 & 1059.82 & 3213.23 & 16613.85 \\
\hline$i_{3}$ & -1403.47 & -1550.52 & -1522.15 & -4687.45 & -1119.75 & -1100.26 & -2407.28 & -8546.31 \\
\hline$j_{3}$ & 249.83 & 248.38 & 117.99 & -2150.07 & 272.60 & 21.05 & -696.65 & -4897.82 \\
\hline$k_{3}$ & 746.96 & 752.75 & 549.84 & 64.63 & 973.96 & 690.02 & 375.71 & -512.38 \\
\hline \multirow[t]{2}{*}{$R^{2}$} & 1.000 & 1.000 & 1.000 & 1.000 & 1.000 & 1.000 & 1.000 & 1.000 \\
\hline & \multicolumn{4}{|c|}{$a / W=0.50$} & \multicolumn{4}{|c|}{$a / W=0.70$} \\
\hline$n$ & 3.36 & 5 & 10 & 20 & 3.36 & 5 & 10 & 20 \\
\hline$a_{3}$ & 249.14 & 533.78 & 1776.00 & 3158.53 & 229.70 & 279.26 & 2760.24 & 1405.21 \\
\hline$b_{3}$ & 212.23 & 395.43 & 1130.02 & 1744.86 & 162.58 & 150.66 & 1748.52 & 721.16 \\
\hline$c_{3}$ & 3978.71 & 8271.47 & 45396.24 & 34334.91 & 3641.17 & 597.95 & 89448.72 & 1029.94 \\
\hline$d_{3}$ & 1289.47 & 3108.55 & 22267.24 & 15737.43 & 1254.01 & -15.45 & 41929.50 & 60.80 \\
\hline$e_{3}$ & -3238.28 & -10709.00 & 69928.74 & -54083.48 & 2581.89 & -1265.29 & 11200.28 & -9996.40 \\
\hline$f_{3}$ & -2158.13 & -5974.54 & 21609.45 & -26648.92 & -512.44 & -72.29 & -17706.68 & -3769.04 \\
\hline$g_{3}$ & -916.99 & 1717.36 & -149241.36 & 14148.96 & -2832.54 & 1040.90 & -95886.54 & 11490.02 \\
\hline$h_{3}$ & 1441.69 & 4111.86 & -62218.02 & 8787.10 & 793.57 & -1.69 & -8662.60 & 4459.88 \\
\hline$i_{3}$ & 2475.96 & 3752.99 & 48808.96 & 4556.94 & 3711.65 & -506.55 & 61540.35 & -4146.87 \\
\hline$j_{3}$ & -237.25 & -956.14 & 27926.11 & 1469.24 & -223.51 & 12.55 & 4367.96 & -1471.51 \\
\hline$k_{3}$ & -479.88 & -1448.88 & 10198.60 & 338.42 & -956.03 & 108.36 & -11629.43 & 223.42 \\
\hline$R^{2}$ & 1.000 & 1.000 & 1.000 & 1.000 & 1.000 & 1.000 & 1.000 & 1.000 \\
\hline
\end{tabular}

However, an analysis of structural elements with defects, which requires estimating their strength or fracture toughness at loads equal to or greater than the limit loads can be performed using the values of the functions $h_{1}{ }^{*}, h_{2}{ }^{*}$ and $h_{3}{ }^{*}$ for the saturation level of the $h_{1}{ }^{*}=f\left(P / P_{0}\right), h_{2}{ }^{*}=f\left(P / P_{0}\right)$ and $h_{3}{ }^{*}=f\left(P / P_{0}\right)$ curves (see Tab.15).

Table 15. The values of the functions $h_{1}{ }^{*}, h_{2}{ }^{*}$ and $h_{3}{ }^{*}$ for the saturation level of the $h_{1}{ }^{*}=f\left(P / P_{0}\right), h_{2}{ }^{*}=f\left(P / P_{0}\right)$ and $h_{3}{ }^{*}=f\left(P / P_{0}\right)$ curves for DEN(T) plates in plane strain.

\begin{tabular}{|c|c|c|c|c|c|c|c|c|c|c|c|c|}
\hline \multirow{2}{*}{$a / W$} & \multicolumn{3}{|c|}{$n=3.36$} & \multicolumn{3}{c|}{$n=5$} & \multicolumn{3}{c|}{$n=10$} & \multicolumn{3}{c|}{$n=20$} \\
\cline { 2 - 14 } & $h_{1}$ & $h_{2}$ & $h_{3}$ & $h_{1}$ & $h_{2}$ & $h_{3}$ & $h_{1}$ & $h_{2}$ & $h_{3}$ & $h_{1}$ & $h_{2}$ & $h_{3}$ \\
\hline 0.05 & 1.593 & 1.236 & 2.957 & 1.743 & 1.552 & 2.572 & 1.900 & 1.840 & 2.244 & 1.966 & 1.945 & 2.105 \\
\hline 0.20 & 2.088 & 1.688 & 3.005 & 2.082 & 1.890 & 2.578 & 2.044 & 1.988 & 2.230 & 2.015 & 1.994 & 2.094 \\
\hline 0.50 & 2.495 & 2.099 & 3.269 & 2.351 & 2.163 & 2.760 & 2.175 & 2.119 & 2.311 & 2.082 & 2.059 & 2.134 \\
\hline 0.70 & 2.858 & 2.601 & 3.614 & 2.601 & 2.487 & 2.907 & 2.310 & 2.261 & 2.376 & 2.152 & 2.125 & 2.166 \\
\hline
\end{tabular}


For DEN(T) plates, whose material characteristics and relative crack length were not considered in this study, the saturation level of the functions $h_{1}{ }^{*}, h_{2}{ }^{*}, h_{3}{ }^{*}$ i.e., $h_{1}{ }^{*}=f\left(P / P_{0}\right), h_{2}{ }^{*}=f\left(P / P_{0}\right)$ and $h_{3}{ }^{*}=f\left(P / P_{0}\right)$, respectively, can be estimated using the following approximation formula

$$
\begin{aligned}
& h^{*}\left(\frac{a}{W}, n\right)=a+b \cdot\left(\frac{a}{W}\right)+c \cdot\left(\frac{1}{n}\right)+d \cdot\left(\frac{a}{W}\right)^{2}+e \cdot\left(\frac{1}{n}\right)^{2}+ \\
& +f \cdot\left(\frac{a}{W}\right) \cdot\left(\frac{1}{n}\right)+g \cdot\left(\frac{a}{W}\right)^{3}+h \cdot\left(\frac{1}{n}\right)^{3}+i \cdot\left(\frac{a}{W}\right) \cdot\left(\frac{1}{n}\right)^{2}+j \cdot\left(\frac{a}{W}\right)^{2} \cdot\left(\frac{1}{n}\right)
\end{aligned}
$$

where the coefficients $a_{. . j}$ are presented in Tab.16, separately for the functions $h_{1}{ }^{*}, h_{2}{ }^{*}$ and $h_{3}{ }^{*}$.

Table 16. The coefficients of Eq.(30) used to determine the functions $h_{1}{ }^{*}, h_{2}{ }^{*}$ and $h_{3}{ }^{*}$ for the saturation level of the $h_{1}{ }^{*}=f\left(P / P_{0}\right), h_{2}{ }^{*}=f\left(P / P_{0}\right)$ and $h_{3}{ }^{*}=f\left(P / P_{0}\right)$ curves for DEN(T) plates under plane strain conditions.

\begin{tabular}{|c|c|c|c|c|c|c|c|c|c|c|c|}
\hline & $a$ & $b$ & $c$ & $d$ & $e$ & $f$ & $g$ & $h$ & $i$ & $j$ & $R^{2}$ \\
\hline$h_{1}{ }^{*}$ & 1.95272 & 1.16633 & -1.51736 & -4.56057 & -1.28208 & 10.58961 & 4.27360 & 1.07612 & -1.21721 & -5.15672 & 0.995 \\
\hline$h_{2}{ }^{*}$ & 1.92995 & 1.57299 & -1.69725 & -5.57726 & -4.05699 & 8.12945 & 4.84571 & 0.45872 & -2.27424 & -0.54159 & 0.993 \\
\hline$h_{3}{ }^{*}$ & 1.97881 & -0.09467 & 2.46079 & 0.60653 & 3.05398 & -2.70106 & -0.63584 & -0.55959 & 7.30248 & 5.02732 & 1.000 \\
\hline
\end{tabular}

\section{Conclusions}

The presented in the paper results complement previous papers of the author [4-6, 16-17] in the range of elastic-plastic fracture mechanics parameters. Extending the analysis of basic parameters, such as the $J$-integral, crack tip opening displacement or load line displacement, allows for the verification of the solutions specified in the 1981 [19], which may be used to solving the some engineering problems in the field of fracture mechanics.

This paper has presented a comprehensive numerical analysis of DEN(T) plates. The study involved verifying the limit load solution by means of a finite element method. New alternative equations were proposed to calculate the limit loads. The level of the selected parameters of in-plane constraints, i.e., the $Q$ stress and the maximum crack opening stress, was determined to simplify the engineering analysis. A discussion was held about the influence of the material properties (yield stress and strain hardening exponent in the RO law) and the relative crack length on the presented parameters of geometric constraints. The selected results for the $Q$-stress and the maximum crack opening stress were approximated using appropriate mathematical formulae. The approximation coefficients were provided in the relevant tables. This paper has also discussed the effect of the material properties and the relative crack length on the numerically determined values of the $J$-integral, the CTOD, and the load line displacement. Using his earlier research results and the discussion presented in the EPRI procedures [19], the author proposed new, alternative models to estimate the value of the selected parameters in the field of fracture mechanics with no need for numerical calculations (J-integral, CTOD, and load line displacement). The numerical results may prove useful in solving various engineering problems which involve estimating the limit loads, the stress distribution near the crack tip, the actual fracture toughness, the current value of the $J$-integral, the CTOD or the load line displacement.

\section{Acknowledgment}

The research presented herein was supported by the Ministry of Science and Higher Education under the IUVENTUS PLUS Program (Grant No. IP2012 011872). 


\section{Nomenclature}

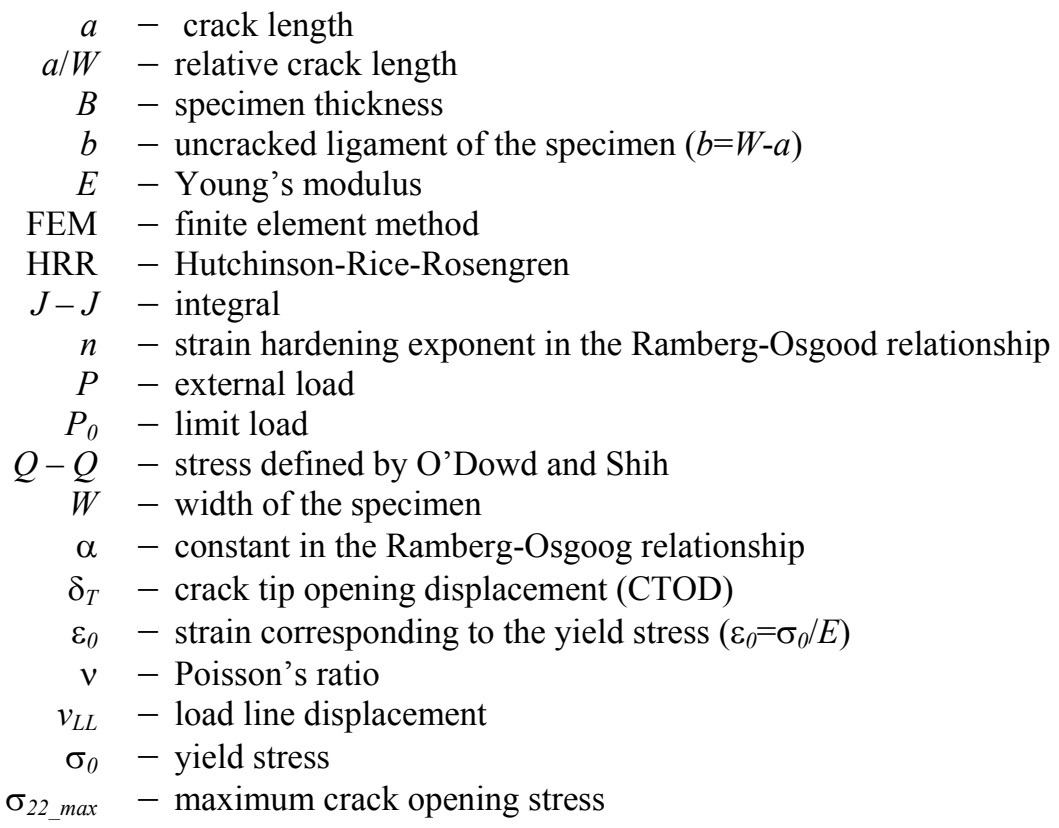

\section{References}

[1] Hutchinson J.W. (1968): Singular behaviour at the end of a tensile crack in a hardening material. - Journal of the Mechanics and Physics of Solids, vol.16, pp.13-31.

[2] Rice J.R. and Rosengren G.F. (1968): Plane strain deformation near a crack tip in a power-law hardening material. - Journal of the Mechanics and Physics of Solids, vol.16, pp.1-12.

[3] Gałkiewicz J. and Graba M. (2006): Algorithm for determination of, $\tilde{\varepsilon}_{i j}(\boldsymbol{n}, \boldsymbol{\theta}), \tilde{\boldsymbol{u}}_{i}(\boldsymbol{n}, \boldsymbol{\theta}), \boldsymbol{d}_{\boldsymbol{n}}(\boldsymbol{n})$ and $\boldsymbol{I}_{\boldsymbol{n}}(\boldsymbol{n})$ functions in Hutchinson-Rice-Rosengren solution and its $3 d$ generalization. - Journal of Theoretical and Applied Mechanics, vol.44, No.1, pp.19-30.

[4] Graba M. (2008): The influence of material properties on the Q-stress value near the crack tip for elastic-plastic materials. - Journal of Theoretical and Applied Mechanics, vol.46, No.2, pp.269-290.

[5] Graba M. (2012): The influence of material properties and crack length on the Q-stress value near the crack tip for elastic-plastic materials for centrally cracked plate in tension. - J. Theor. Appl. Mech., vol.50, No.1, pp.23-46.

[6] Graba M. (2011): The influence of material properties and crack length on the Q-stress value near the crack tip for elastic-plastic materials for single edge notch plate in tension. - Archives of Civil and Mechanical Engineering, vol.11, No.2, pp.301-319.

[7] O'Dowd N.P., Shih C.F. (1991): Family of crack-tip fields characterized by a triaxiality parameter - I. Structure of fields. - J. Mech. Phys. Solids, vol.39, No.8, pp.989-1015.

[8] O’Dowd N.P., Shih C.F. (1992): Family of crack-tip fields characterized by a triaxiality parameter - II. Fracture applications. - J. Mech. Phys. Solids, vol.40, No.5, pp.939-963.

[9] SINTAP Procedure: Structural Integrity Assessment Procedures for European Industry. Final Procedure, BriteEuram Project No BE95-1426. - Rotherham: British Steel, 1999.

[10] Kocak M., Webster S., Janosch J.J., Ainsworth R.A. and Koers R. (2006): FITNET Report, (European Fitness-forservice Network), Contract No. G1RT-CT-2001-05071.

[11] O'Dowd N.P. (1995): Applications of two parameter approaches in elastic-plastic fracture mechanics. Engineering Fracture Mechanics, vol.52, No.3, pp.445-465. 
[12] Ritchie R.O., Knott J.F. and Rice J.R. (1973): On the relationship between critical tensile stress and fracture toughness in mild steel. - Journal of the Mechanics and Physics of Solids, vol.21, pp.395-410.

[13] Neimitz A., Graba M. and Gałkiewicz J. (2006): New formulation of the Ritchie, Knot and Rice hypothesis. Proceedings of XVI ECF; Alexandrea - Greece, article in electronic version.

[14] Neimitz A., Graba M. and Gałkiewicz J. (2007): An alternative formulation of the Ritchie-Knott-Rice local fracture criterion. - Engineering Fracture Mechanics, vol.74, pp.1308-1322.

[15] Graba M. (2009): Numerical Analysis of the Mechanical Fields Near the Crack Tip in the Elastic-Plastic Materials. 3D Problems. - PhD dissertation, Kielce University of Technology - Faculty of Mechatronics and Machine Building, 387 pages, Kielce 2009 (in Polish).

[16] Graba M. (2013): Catalogue of maximum opening crack stress for CCT specimen assuming large strain condition. - Central European Journal of Engineering, SPRINGER, DOI: 10.2478/s13531-012-0063-8, 2013.

[17] Graba M. (2012): Catalogue of the numerical solutions for SEN(B) specimen assuming the large strain formulation and plane strain condition. - Archives of Civil and Mechanical Engineering, Published by Elsevier, vol.12, No.1, pp.29-40.

[18] Graba M. and Gałkiewicz J. (2007): Influence of the crack tip model on results of the finite elements method. Journal of Theoretical And Applied Mechanics, (ISI Master List), vol.45, No.2, pp.225-237, Warsaw 2007.

[19] Kumar V., German M.D. and Shih C.F. (1981): An engineering approach for elastic-plastic fracture analysis. Electric Power Research Institute, Inc. Palo Alto, CA (1981), EPRI Report NP-1931.

[20] Graba M. (2012): Verification of the hybrid solution to determining the J-integral using EPRI procedures. Proceeding of XXIV Symposium on the Fatigue and Fracture Mechanics, Bydgoszcz - Pieczyska, in Polish, article in an electronic form.

[21] Chauhan S., Chattopadhyay J. and Dutta B.K. (2016): Limit load equations for miniature single edge notched tensile specimens. - Transactions of the Indian Institute of Metals, vol.69, No.2, pp.641-646.

[22] ADINA 8.8, ADINA: User Interface Command Reference Manual - Volume I: ADINA Solids \& Structures Model Definition, Report ARD 11-2, ADINA R\&D, Inc., 2011.

[23] ADINA 8.8, ADINA: Theory and Modeling Guide - Volume I: ADINA Solids \& Structures, Report ARD 11-8, ADINA R\&D, Inc., 2011.

[24] Neimitz A., Dzioba I., Gałkiewicz J. and Molasy R. (2004): A study of stable crack growth using experimental methods, finite elements and fractography. - Engineering Fracture Mechanics, vol.71, pp.1325-1355.

[25] Brocks W., Cornec A. and Scheider I. (2003): Computational aspects of nonlinear fracture mechanics. Bruchmechanik, GKSS-Forschungszentrum, Geesthacht, Germany, Elsevier pp.127-209.

[26] Brocks W. and Scheider I. (2003): Reliable J-values. Numerical aspects of the path-dependence of the J-integral in incremental plasticity. - Bruchmechanik, GKSS-Forschungszentrum, Geesthacht, Germany, Elsevier pp.127-209.

[27] Shih C.F. (1981): Relationship between the J-integral and the crack opening displacement for stationary and extending cracks. - Journal of the Mechanics and Physics of Solids, vol.29, pp.305-329.

[28] Chao Y.J., Zhu X.K., Kim Y., Lar P.S., Pechersky M.J. and Morgan M.J. (2004): Characterization of crack-tip field and constraint for bending specimens under large-scale yielding. - International Journal of Fracture, vol.127, pp.283-302.

[29] TableCurve 3D version 4.0.0, 1993-2002.

[30] Neimitz A., Dzioba I., Graba M. and Okrajni J. (2008): The assessment of the strength and safety of operation of high temperature components containing crack. - Kielce University of Technology Publishing House, Kielce.

[31] Graba M.: Proposal of the hybrid solution to determining the selected fracture parameters for SEN(B) Specimens dominated by plane strain. - Bulletin of the Polish Academy of Sciences - Technical Sciences, accepted for print in 2017.

Received: June 16, 2016

Revised: November 8, 2016 